\title{
A New Fusion of Salp Swarm with Sine Cosine for Optimization of Non-linear Functions
}

\author{
Narinder Singh $^{1}$, Le Hoang Son ${ }^{2 *}$, Francisco Chiclana ${ }^{3}$, Jean-Pierre Magnot ${ }^{4}$ \\ ${ }^{1}$ Department of Mathematics, Punjabi University, Patiala-147002, Punjab, India \\ narindersinghgoria@ymail.com \\ ${ }^{2}$ VNU Information Technology Institute, Vietnam National University, Hanoi, Vietnam \\ sonlh@vnu.edu.vn \\ ${ }^{3}$ School of Computer Science and Informatics, De Montfort University, The Gateway, Leicester, LE1 9BH UK \\ chiclana@dmu.ac.uk \\ ${ }^{4}$ LAREMA, universitéd' Angers, 2 boulevard Lavoisier49045 Angers cedex 01, France \\ jean-pierr.magnot@ac-clermont.fr \\ *: Corresponding author. Tel.: (+84) 904.171.284. Address: 144 Xuan Thuy, Cau Giay, Hanoi, Vietnam
}

\begin{abstract}
The foremost objective of this article is to develop a novel hybrid powerful meta-heuristic that integrates the Salp Swarm Algorithm with Sine Cosine Algorithm (called HSSASCA) for improving the convergence performance with the exploration and exploitation being superior to other comparative standard algorithms. In this method, the position of salp swarm in the search space is updated by using the position equations of sine cosine; hence the best and possible optimal solutions are obtained based on the sine or cosine function. During this process, each salp adopts the information sharing strategy of sine and cosine functions to improve their exploration and exploitation ability. The inspiration behind incorporating changes in Salp Swarm Optimizer Algorithm is to assist the basic approach to avoid premature convergence and to rapidly guide the search towards the probable search space. The algorithm is validated on twenty-two standard mathematical optimization functions and three applications namely the three-bar truss, tension/compression spring and cantilever beam design problems. The aim is to examine and confirm the valuable behaviors of HSSASCA in searching the best solutions for optimization functions. The experimental results reveal that HSSASCA algorithm achieves the highest accuracies with least runtime in comparison with the others.
\end{abstract}

Keywords: Standard global Optimization Functions; Heuristic Hybridization; Salp Swarm Algorithm; Sine Cosine Algorithm; Exploration and Exploitation. 


\section{INTRODUCTION}

Nature inspired techniques are powerful and well-known for searching optimal solutions in optimization problems. Day by day, researchers have developed several newly meta-heuristics for improving and enhancing exploration and exploitation of the existing algorithms, for instance Gravitational Search Algorithm (GSA) [15], Grey Wolf Optimization (GWO) [30], Particle-Swarm-Optimization (PSO) [23], Ant-Colony-Optimization- (ACO) [3], Krill Herd Algorithm (KHA) [37], Ant Lion Optimizer (ALO) [36] and many others [1, 4, 5, 7, 8, 11-13, 17, 21, $22,25,29,31-35,38-39,42,44-52,53-54,58,61,84]$. Each nature inspired algorithm has its own advantages and disadvantages so that there is no guarantee which algorithm is best suited for a specific problem [57]. It is possible that the single optimizer algorithm cannot find the best solution for each type of functions [57]. Therefore, implementing and proposing new and high-accuracy meta-heuristics for real applications have become a challenging task for scientists [9].

Hybridization of nature inspired algorithms is a popular approach for to merge merits and strength of standalone algorithms for handling those deficiencies [9]. Several typical studies can be seen in [21, 38, 42, 44, 47, 50,61, 82, 83] in which the hybrid algorithms merging advantages of single ones performed well in boosting the accuracy of functions and reducing classification time. As an example, Sarbazfard et al. [42] developed a hybrid variant called HFADE that integrates differential evolution (DE) with Firefly algorithm (FA) for improving exploration tendency of those algorithms. Firefly algorithm and differential evolution both are effective techniques but firefly approach depends on arbitrary instructions for hunt, which lead into retardation in searching the superior and possible global result in the search area. The existing variant was utilized on twenty-six standard functions for testing the convergence accuracy. Fouad [17] recently proposed a hybrid approach called Hybrid GWO-GA, amid the grey wolf optimizer (GWO) and genetic algorithm (GA) in order to minimize a simplified model of the energy function of the molecule. In this study, GWO was applied to create the equilibrium amid exploration and exploitation in the existing variant. The experiments revealed that the existing approach is more competent, capable and promising of searching nearest global optima minimum value of the standard problem than the others.

However, there are several meta-heuristics applied in real-world problems and no algorithm can solve all types of functions [2]. In this paper, we consider the extension of the salp swarm (SSA) [28], which is a robust algorithm in comparison with the other algorithms. It has good convergence rate, but there are still some shortcomings/demerits, like easy fall into low exploration, local optimum, poor solution accuracy, premature convergence and exploitation tendency [43]. Faris et al. [16] was presented an newly modified approach for enhance the performance of SSA algorithm. In this work two new wrapper FS algorithms that apply SSA as the search method. Firstly, eight transfer problems/or functions are employed to convert the continuous version of salp swarm algorithm to binary. And secondly, the crossover operator is applied in addition to the transfer problems/or functions enhanced the exploratory behavior of the approach. The working performance of this version have been tested on 22 standard problems and verified with several latest meta-heuristics in term of best and possible solution of functions. In order to handle these drawbacks, we propose the idea of combination between salp swarm and sine cosine algorithms (SCA) [34], which is competent for determining best solution with the exploitation and exploration being superior to other recent comparative standard algorithms [56]. Farnad and Jafarian [77] presented an efficient hybrid method for finding the solutions of engineering and constrained numerical functions. Three different algorithms such as genetic algorithm (GA), particle swarm optimization (PSO) and symbiotic organisms were integrated for finding solutions of function in a complex design space and to manage the feasibility of searching with penalty function strategy. The new algorithm was tested on the standard well-known functions and engineering applications with the recent meta-heuristics. Similarly, several recent hybrid, modified and newly evolutionary approaches have been presented by the researchers such as Hybrid Bacterial Flower Pollination Algorithm (HBFPA) [78], Flower Pollination Algorithm (FPA) [79], Hybrid whale optimization algorithm based on local search strategy [80], hybrid Q-learning sine-cosine- based strategy (QLSCA) [81], Adaptive Operator Quantum-Behaved Pigeon-Inspired Optimization Algorithm [85] and many others. 
The main objective of this work is to present a hybrid salp swarm optimizer with sine cosine algorithm to solve engineering problems. This proposed method is called as hybrid SSASCA algorithm. Although the salp swarm algorithm is more capable to reveal a competent accuracy in comparison with other well-known meta-heuristics, it still may face the difficulty of getting trapped in local optima. It is also not fitting for high complex functions and cannot handle several their drawbacks such as premature convergence, slow diversity, slow convergence speed etc. Hence, in order to improve the slow convergence and other weakness of the salp swarm approach, SCA is invoked as a local search scheme. The proposed method transits from (exploration to exploitation) the search of solved with the use of optimal range in the trigonometry functions. Therefore, HSSASCA algorithm produces and refines a set of random optimal goals for the given functions and furthermore it intrinsically advantages from the local optima avoidance and high exploration compared to separate based meta-heuristics. Our methodology enhances search capabilities and global convergence rate by accelerating the search speed. The modified method has been tested on several well-known standard benchmark functions and engineering applications in the comparison with the related algorithms. All numerical and statistical optimal solutions of the functions reveal that the proposed method outperforms the others for searching the best value of the functions.

The remains are below: Section 2 describes the background of Salp Swarm and Sine Cosine. The motivation of the present work has been reported in the section 3. Section 4 shows details of the newly hybrid approach. Analysis and comparative experiments are described in Sections 5-6. In Section 7, three applications namely the three-bar truss, tension/compression spring and cantilever beam design problems are presented. Finally, Section 8 presents the concluding remarks and future studies.

\section{BACKGROUND}

\subsection{Salp Swarm Algorithm (SSA)}

Mirazalii et al. [28] introduced an extensive accessibility such as SSA, inspired from the navigation and foraging behavior of salp deep in the sea. These organisms attach roots and make a root or a slip chain. The salp chain tries to find the best place of food via process of searching with the help of a leader salp, as the rest of the followers. The crowd of salp swarm optimizer algorithm is initialized in two different groups like followers and leader. The first group is one salp taking the position at the front of the sequence. Let $y$ denoted as position of a salp, and $F$ represents food. Position of leader is updated as,

$$
x_{j}^{1}= \begin{cases}F_{j}+c_{1}\left(\left(u b_{j}-l b_{j}\right) c_{2}+l b_{j}\right) & c_{3} \geq 0.5 \\ F_{j}-c_{1}\left(\left(u b_{j}-l b_{j}\right) c_{2}+l b_{j}\right) & c_{3}<0.5\end{cases}
$$

where $x_{j}$ is the position of the best solution, $u b_{j}$ and $l b_{j}$ are upper and lower bound of the $j^{t h}$ dimension, $F_{j}$ is the food source position of the dimension and $c_{2}, c_{3}$ are random numbers,

Here, $c_{1}$ is an important constant that it maintains a balance amid exploitation and exploration, and it can be written/or given by:

$$
c_{1}=2 e^{-\left(\frac{4 l}{L}\right)^{2}}
$$

where $L$ is the maximum number of iteration and $l$ is the current iteration.

The follower's positions are updated by using the following mathematical equation:

$$
x_{j}^{i}=\frac{1}{2} a t^{2}+v_{0} t
$$


where $i \geq 2, x_{i}^{j}$ presents the position of $i^{\text {th }}$ followers salp in $j^{\text {th }}$ dimension, $t$ is time, $v_{0}$ is the initial speed and $a=\frac{v_{\text {final }}}{v_{0}}$ where $v=\frac{x-x_{0}}{t}$.

Hence, the time in optimization in generation or iteration, the discrepancy between generations or iterations is equal to 1 , and considering $v_{0}=0$, this equation can be expressed as follows:

$$
x_{j}^{i}=\frac{1}{2}\left(x_{j}^{i}+x_{j}^{i-1}\right)
$$

where $x_{j}^{i}$ is the position of the $i^{t h}$ follower at the $j^{\text {th }}$ dimension.

\subsection{Sine Cosine Algorithm (SCA)}

SCA [34] establishes various basic random agent solutions based on sine-cosine functions towards the best global optima. Main step of an optimizer is known to be the formulation of the position updating. Subsequent position of an agent is modified by:

$$
\begin{gathered}
\vec{x}_{i}^{t+1}=\vec{x}_{i}^{t}+r_{1} \times \sin \left(r_{2}\right) \times\left|r_{3} \times l_{i}^{t}-\vec{x}_{i}^{t}\right| \\
\vec{x}_{i}^{t+1}=\vec{x}_{i}^{t}+r_{1} \times \cos \left(r_{2}\right) \times\left|r_{3} \times l_{i}^{t}-\vec{x}_{i}^{t}\right|
\end{gathered}
$$

The conditions in equations (4-5) for exploitation and exploration are:

$$
\vec{x}_{i}^{t+1}= \begin{cases}\vec{x}_{i}^{t}+r_{1} \times \sin \left(r_{2}\right) \times\left|r_{3} \times l_{i}^{t}-\vec{x}_{i}^{t}\right| & , r_{4}<0.5 \\ \vec{x}_{i}^{t}+r_{1} \times \cos \left(r_{2}\right) \times\left|r_{3} \times l_{i}^{t}-\vec{x}_{i}^{t}\right| & , r_{4} \geq 0.5\end{cases}
$$

where $\vec{x}_{i}^{t}$ is the current position at $t^{\text {th }}$ iteration in $i^{\text {th }}$ dimension, $l_{i}$ is the targeted global optimal solution, $r_{1}, r_{2}, r_{3}$ are random numbers and || is the absolute value.

In order to get a balance amid exploitation and exploration, the first random value is chosen adaptively as follows.

$$
r_{1}=\text { constant }- \text { present_iter } \times \frac{\text { constant }}{\text { Max_iter }}
$$

The first random value $\left(r_{1}\right)$ controls the new update position's region. The second random value $\left(r_{2}\right)$ decides the distance outwards or towards the destination. The third random value $\left(r_{3}\right)$ generates a random weight to stochastically deemphasize $\left(r_{3}<1\right)$ or emphasize $\left(r_{3}>1\right)$ effect of destination in defining the distance. The fourth random value is in $[0,1]$ and uniformly switches amid the cosine and sine position updating.

\section{Motivation of the present work}

Although SSA is skilled to conceal well-organized accuracy in comparison with recent meta-heuristics, it is still may face the difficulty of getting trapped in local optima and is not fit for highly complex functions. To extent its search ability and overcome these limitations, a newly hybrid method called hybrid salp swarm optimizer and sine cosine algorithms (HSSASCA) algorithm is developed to solve engineering problems. During this work, SSA operates in the direction of exploring the vector of solutions while SCA is invoked as a local search scheme to improve the solution superiority. The natural characteristic of SCA algorithm to make compound mutation in the optimal solutions and to avoid to stuck in local optima. By this methodology, it is intended to improve the global convergence by accelerating the search seeking instead of letting the algorithm running several iterations without any improvement. The accuracy of the proposed method has been tested on various standard well-known benchmark and engineering functions. Experimental results reveal that the proposed approach is a robust search method for several optimization functions. 


\section{THE PROPOSED HSSASCA ALGORITHM}

Researchers have been trying for developing new hybrid and modified version of the exiting algorithms for different specific complex functions of optimization problems. As per Talbi [86], two different algorithms can be hybridized in two ways such as low level versus high level and relay versus teamwork (sub-categories (i) low-level relay hybrid (LRH) and (ii) low-level teamwork hybrid (LTH) with co-evolutionary techniques as homogeneous. During this research, we hybridize the salp swarm algorithm with sine cosine algorithm using low-level teamwork hybrid (LTH) co-evolutionary mixed hybrid. Further, the main structure of the proposed hybrid method is explained. It is known as HSSASCA, which merges the Salp Swarm Algorithm (SSA) and the Sine Cosine Algorithm (SCA). The main part of the Salp Swarm Algorithm is modified by improving the updating phase of the population's position. In this modification the sine and cosine functions have been applied in the position update equation in SSA algorithm for enhancing the exploration and exploitation tendency of the algorithm. This integration adds more flexibility to the Salp Swarm Algorithm (SSA) in exploring the crowd/or population and ensures the diversity of it, as well as the appropriate value reaches quickly.

Further, during this study, a modified approach of hybrid SSA and SCA is incorporated in a parallel manner with the objective to replace bad optimal solutions via the one-to-one idea to find new crowd/or population. The main motive of this work is that the help of salp swarm can be improved exploitation tendency and exploration can be achieved with the help of sine and cosine. The proposed method uses trigonometry functions (i.e. sine and cosine) to search and exploit space between two solutions in the search area for finding a better optimal solution. The agent/or salp population and fitness value of the given function has been evaluated as per the newly hybrid method. Furthermore, the position of the each salp swarm in the entire group is improved by applying the position equations of sine and cosine functions. For this reason, better quality of global optimal results/or solutions have been tried to update based on these functions, which means that the exploration ability could be much stronger. The sine and cosine functions can more helps the Salp Swarm Optimization algorithm phase to attained the best solution/ or score more rapidly and improve the convergence rate.

Through that methodology, the natural properties of this improvement can be controlled by involving the SCA phase as a local research strategy which accelerates the behavior of the desire and prevents the system of metabolic modification without any modifications in the results. Indeed, the inefficiency of the SSA phase can be reduced efficiently. Here, the proposed algorithm proceeds to find the best and possible results in the search areas. Further, brief details of the newly hybrid approach is shown step by step as below:

\section{Step 1: Initialization population}

During this study, firstly we initialize the population in the search area. The crowds of salp are initialized randomly within the search area of the given functions, where the meta-heuristic assigns a random vector of $n$ dimensional for the $i^{\text {th }}$ salp; $X=x_{i} \sim(i=1,2,3, \ldots, n)$.

\section{Step 2: Evaluation}

Every search member is evaluated according to the superiority of its position/or location which is allied to the preferred objective problem/or function, where the best solution (or goal) so far is obtained.

\section{Step 3: Each agent locations/or positions updating}

The following equation (9) affirmed that the leader only updates its position or location with respect to the food source. It is most important role of this parameter in SSA algorithm, since it creates balancing between exploration and exploitation. The sine and cosine functions have been applied to this parameter to enhance the convergence rate and balance between exploration and exploitation. The position equation of SSA algorithm has been modified as follows:

$$
x_{j}^{1}= \begin{cases}F_{j}+\sin \left(r_{2}\right) \times\left|c_{1} \times F_{j}-S_{j}\right| & c_{3}<0.5 \\ F_{j}+\cos \left(r_{2}\right) \times\left|c_{1} \times F_{j}-S_{j}\right| & c_{3} \geq 0.5\end{cases}
$$


where $x_{j}^{1}$ is the position of the best solution at the $j^{\text {th }}$ dimension, $F_{j}$ is the food position at the $j^{t h}$ dimension,

$S_{j}$ is the salp position at the $j^{t h}$ dimension and random number is $r_{2}=(2 \times \pi) \times \operatorname{rand}()$. The parameter $c_{3}$ is random numbers uniformly generated in the interval of $[0,1]$. In fact, they dictate if the next position in $j^{\text {th }}$ dimension should be towards positive infinity or negative infinity as well as the step size.

\section{Step 4: Followers locations/or positions updating}

The position update in equation (4) of the followers has been modified as equation (10). This methodology helps the best position value of the salp $\left(S_{j}\right)$ in the entire swarm during the searching of the best goal for a given function have been directly providing best position scores in that equation for the enhancing the convergence rate and defeating the premature convergence. The update the position of the followers by following equations:

$$
x_{j}^{i}=\frac{1}{2}\left(x_{j}^{i}+x_{j}^{i-1}\right)+S_{j}
$$

where $x_{j}^{i}$ is the position of the $i^{t h}$ follower at the $j^{\text {th }}$ dimension, $S_{j}$ is the salp position at the $j^{\text {th }}$ dimension.

\section{Step 5: Stopping condition}

Finally, the stopping criteria have been applied for calculating the final optimal solution of the given functions. By the procedure of evaluating each agent/or salp assessment process and updating the best agent's place, it will be repeated again and again until it satisfies the criteria of prevention. i.e. it reaches to the highest number of generations/or iterations or the global optimal result/or goal is earliest found.

The first optimization process is to search optimal results using salp Swarm. Then, the position update equation of Sine and Cosine is used to refine the position of leader and followers during the search process. The rest of operations are the same as Salp Swarm. Algorithm 1 shows the HSSASCA flow.

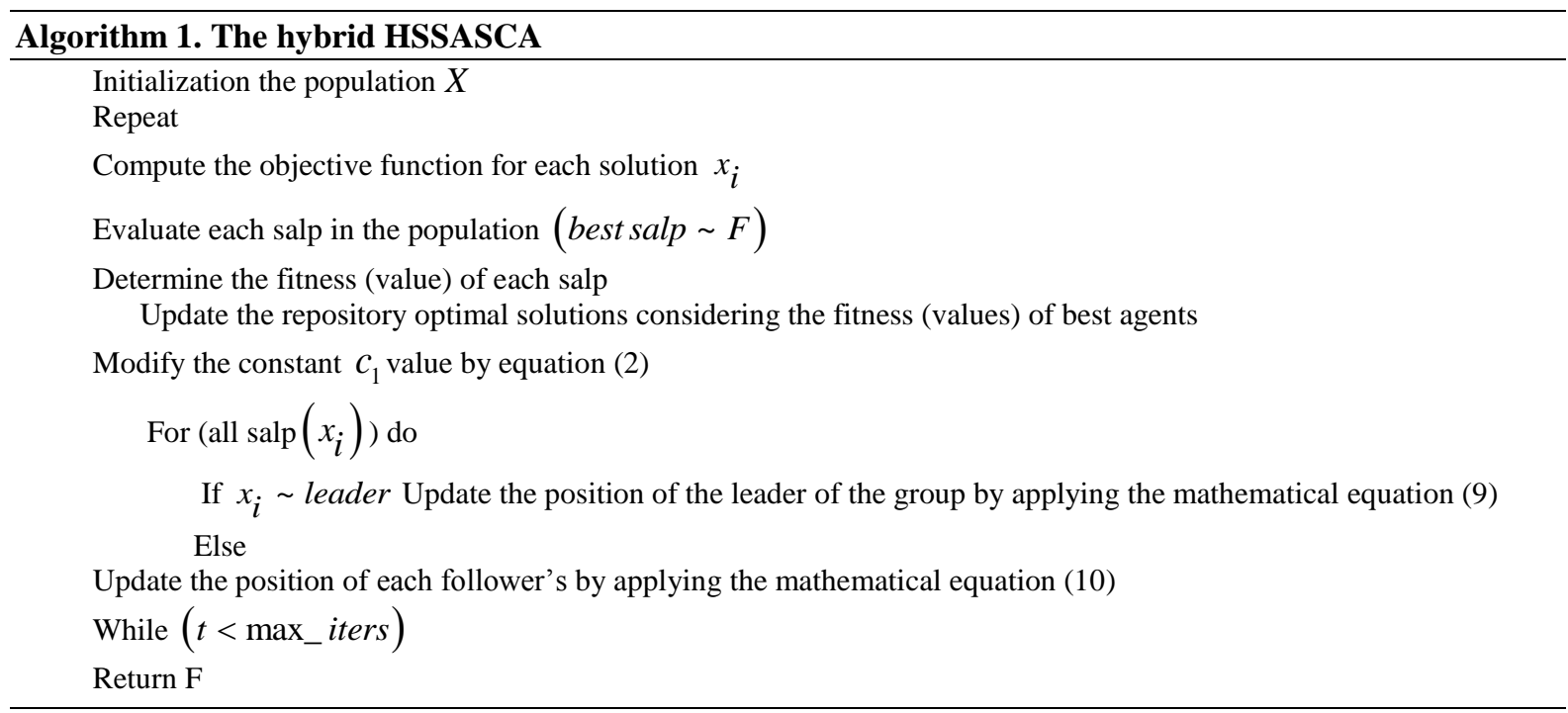

The procedure of the proposed method is shown in algorithm 1. For the basic computational complexity of the Salp Swarm Algorithm (SSA) is of $O(t(d * n+\operatorname{Cof} * n))$, where $d$ is the number of variables (dimension), $t$ shows the number of iterations, Cof presents the cost of objective function and $n$ is the number of solutions. The time complexity of performing sine and cosine operations is of 
$O\left(\max \_\right.$iters $\left.* n * d\right)$, where max_iters is the maximum number of iterations or generations. Hence, the time complexity of the proposed algorithm (HSSASCA) is:

$$
O(t(d * n+\operatorname{Cof} * n))+O\left(\max \_ \text {iters } * n * d\right) .
$$

Obviously, the time complexity of the proposed algorithm is higher than that of the standard salp swarm algorithm (SSA) while both of them are in the same order of magnitude.

With the above strategy, the newly hybrid approach hypothetically is competent to determine the global optimum of the optimization function due to the following reasons:

- In HSSASCA, the disparate regions of the search area are explored, when the cosine and sine trigonometry functions return an optimal solution less than negative one $(-1)$ or greater than positive one $(+1)$.

- In HSSASCA, the encouraging regions of the search area is exploited when the trigonometry function gives optimal solution amid negative one (-1) and positive one (+1).

- HSSASCA algorithm produces and refines a set of random optimal goals for the given function. Hence, it intrinsically advantages from the local optima avoidance and high exploration compared to separate based meta-heuristics.

- The HSSASCA approach transits from (exploration to exploitation) the search of solved with the use of optimal range in trigonometry functions.

- The finest estimate of the comprehensive optimum is stored in a variable as the target point and not at all gets mislaid throughout optimization.

- Because the optimal solutions always update their conditions around the best solution they have ever received, there is a trend toward the best areas of search during optimization.

- Because the newly proposed method considers the compatibility problem as a black box, the problems can be easily added in different areas, which are under the solution to the right problem.

\section{ANALYSIS}

The proposed algorithm has been applied on well-known standard and engineering optimization functions. Here these functions have been chosen for verifying our experimental solution with recent meta-heuristics. All the results are illustrated in Tables 2-10. Further, the experimental results/or solutions of the hybrid method are verified/or compared against the SSA (Salp Swarm Algorithm), PSO (Particle Swarm Optimization), MFO (Moth-Flame Optimization Algorithm), SCA (Sine Cosine Algorithm), DA (Dragonfly Algorithm), MVO (Multi-Verse Optimizer), ALO (Ant Lion Optimizer), MGWO (Mean Grey Wolf Optimizer), DCSGWO (Distributed Compressed Sensing + Grey Wolf Optimizer), FWAGWO (Fireworks Algorithm + Grey Wolf Optimizer) and HAGWO (Hybrid Algorithm of Grey Wolf Optimizer) algorithms.

The HSSASCA (Hybrid Salp Swarm Algorithm + Sine Cosine Algorithm), SSA, PSO, MFO, SCA, DA, MVO, ALO, MGWO, DCSGWO, FWAGWO and HAGWO algorithms are programmed by MATLAB 2015 and implemented on, 15.6" Intel HD Graphics, Pentium-Intel Core (TM), 16.9 HD LCD, 3GB Memory, 320 GB HDD and i5 Processor $430 \mathrm{M}$.

Massive experiments illustrate that the SCA and SSA techniques can be close to the best condition on these problems/functions when the number of generation/iteration and population size are set to 300 and 30, respectively. For a fair comparison, the swarm size and the number of generations must be the same for all variants used and should also 30 runs each algorithm for check the quality.

Hence, in this work, the same numbers of generation and population size were used for SSA, PSO, MFO, SCA, DA, MVO, ALO, MGWO, DCSGWO, FWAGWO, HAGWO and HSSASCA. Parameter settings for these techniques are listed in Table 1. 
Table1. Parameter settings

\begin{tabular}{|c|c|}
\hline Algorithm & Parameters \\
\hline SSA & Set as in [28] \\
\hline \multirow[t]{2}{*}{ PSO } & $s=30$, max_iter $=300$ \\
\hline & $v_{\max }=6, c_{1}=c_{2}=2, w_{\max }=0.9$ and $w_{\min }=0.2$ \\
\hline MFO & $s=30$, max_iter $=300$, remaining by $[33]$ \\
\hline SCA & $s=30$, max_iter $=300, a=2$ \\
\hline DA & $s=30$, max_iter $=300$, remaining by [31] \\
\hline MVO & $s=30$, max_iter $=300$, remaining by [29] \\
\hline ALO & $s=30$, max_iter $=300$, remaining by $[36]$ \\
\hline MGWO & $s=30$, max_iter $=300$, remaining by [53] \\
\hline DCSGWO & $s=30$, max_iter $=300$, remaining by $[25]$ \\
\hline FWAGWO & $s=30, \max \_$iter $=300$, remaining by [46] \\
\hline HAGWO & $s=30$, max_iter $=300$, remaining by [5] \\
\hline \multirow[t]{3}{*}{ HSSASCA } & $s=30$, max_iter $=300, c_{1}, c_{2}, c_{3} \in[0,1]$ \\
\hline & $r_{1}=2 \pi \times \operatorname{rand}(), r_{2}=2 \times \operatorname{rand}(), v_{0}=0$ and \\
\hline & $I_{\text {runs }}=30$ \\
\hline
\end{tabular}

Hence, the hybrid HSSASCA algorithm has been investigated on the tested functions. The uni-modal problems/or tasks are well-known to have only one global optimum and thus can be used to assess the exploitation capability of a meta-heuristic. Regularly having more than one local optimum, multi-modal and fixed-dimension multi-modal problems/or tasks are applied/or used to assess the exploration capability of a meta-heuristic. The proposed algorithm was run 20 times on each benchmark problem. The statistical and numerical solutions have been performed to illustrate that. By best parameter settings, it was found that the best solutions or results of the given functions lie within a reasonable number of generations/ or iterations. The different criteria in this work have been applied to assess the capability of proposed algorithm and others. The statistical values such as average and standard deviation have been used to assess the reliability of the algorithms. Further, the minimum and maximum value of the objective function represent the best possible cost of the given problem in the number of iterations. The average number of function evaluation of the successful runs and average computational time of the successful runs has been utilized to found the best cost of the problems.

For seven uni-modal problem, the quality of solution of the given functions obtained have been illustrated by the best score, max or min objective function value, average, standard deviation, self and total cpu time respectively. These obtained results are reported in table 2 and the convergence performance of the algorithms is shown in figure 2. Further, the accuracy of the algorithms has been verified on six multi-modal and nine fixed dimension functions. The experimental solutions of these functions and convergence performance of the algorithms are presented in table 3-4 and figure 3-4 respectively. At the end, we have solved the optimization engineering problems for verifying the performance of the algorithms and the brief details of these problems and solutions are reported in the section 7 .

\section{DISCUSSION ON EXPERIMENTAL RESULTS}

\subsection{Convergence performance of the Algorithms}

The convergence performance of the HSSASCA algorithm and the others are presented for tested functions by plotting the standard function values against the-number of generations/or iterations as present in Figure 1. The red line represents the accuracy and performance of the standard SSA algorithm, whereas the black line represents the accuracy and performance of the HSSASCA algorithm. The data in Figure 1 are plotted after d-iterations. The convergence performance of the algorithm proves that the new hybrid method is superior than the standard SSA algorithm and other meta-heuristics. This confirms that the applied partitioning mechanism and the integration 
Narinder Singh et al.

between the SSA and SCA algorithm can accelerate the convergence of the proposed algorithm. Here, we concluded that the modification reduces the running time of the algorithms and boosts the accuracy of classification problems.
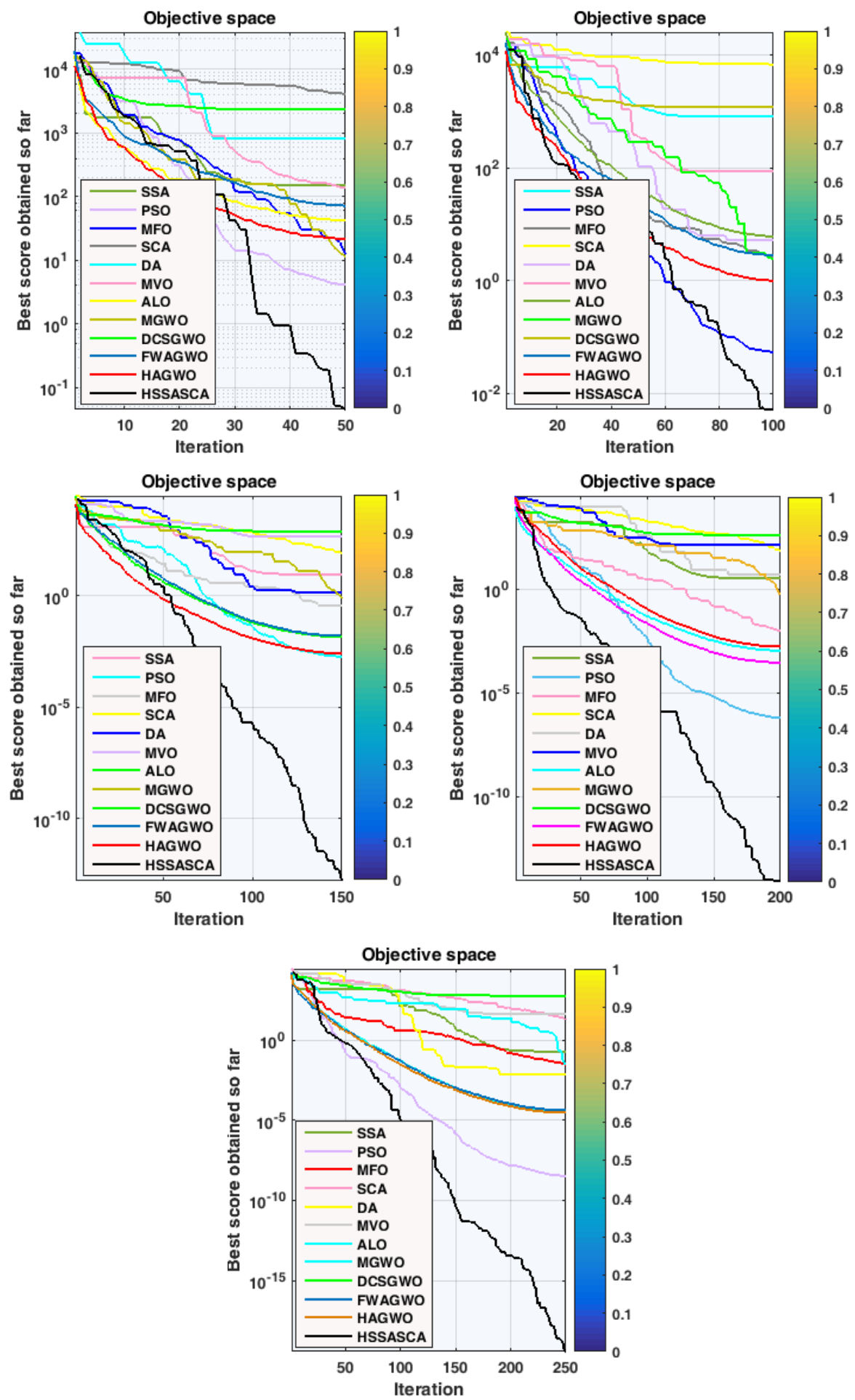

Figure 1. Convergence performance of algorithms on different dimensions 


\subsection{Standard Functions}

The working accuracy of the hybrid HSSASCA algorithm has been confirmed on uni-modal, multi-modal and fixed dimension multi modal tested standard problems/or functions. The tested functions are presented in Appendix (Tables A - C).

\subsection{Uni-modal Test Functions}

In this subsection, the ability of the proposed method has-been-tested on uni-modal problems/or functions. The obtained solutions of these functions have been discussed in Table 2 and Figure 2. For verifying the performance and ability of the hybrid algorithms, we have used the standard PSO, SSA, MFO, SCA, DA MVO, ALO, MGWO, DCSGWO, FWAGWO and HAGWO algorithms. The best optimal solutions are written in bold font. Here, it-can-be easily seen-that-the newly proposed approach provides better or highly effective global optimal results as compared to other recent comparative algorithms. As previously discussed, these functions are more capable for benchmarking exploitation of the meta-heuristics. Therefore, it is evidence that the proposal achieves high rate of exploitation capability.

Table 2. Results of SSA, PSO, MFO, SCA, DA, MVO, ALO, MGWO, DCSGWO, FWAGWO, HAGWO and HSSASCA algorithms on seven Uni-modal functions at different iterations

\begin{tabular}{|c|c|c|c|c|c|c|c|c|}
\hline $\begin{array}{l}\text { Fun. } \\
\text { No. }\end{array}$ & Algorithm & $\begin{array}{l}\text { Best } \\
\text { Score }\end{array}$ & Min Value & $\begin{array}{c}\text { Max } \\
\text { Value }\end{array}$ & Mean & S.D. & $\begin{array}{c}\text { Self Time } \\
(\mathrm{s})\end{array}$ & $\begin{array}{c}\text { Total Time } \\
\text { (s) }\end{array}$ \\
\hline \multirow[t]{12}{*}{1.} & SSA & 0.2759 & 0 & $2.0834 \mathrm{e}+04$ & $3.9077 e+03$ & $4.4991 e+03$ & 0.795 & 0.858 \\
\hline & PSO & 0.0598 & 0.0598 & $6.7880 \mathrm{e}+04$ & $1.4489 \mathrm{e}+03$ & $7.0965 e+03$ & 0.950 & 1.029 \\
\hline & MFO & 184.2208 & 184.2208 & $7.6447 \mathrm{e}+04$ & $1.3452 \mathrm{e}+04$ & $1.8670 \mathrm{e}+04$ & 0.935 & 1.108 \\
\hline & SCA & 130.2639 & 0 & $6.8458 \mathrm{e}+04$ & $2.2581 \mathrm{e}+04$ & $2.9145 \mathrm{e}+04$ & 0.872 & 0.952 \\
\hline & DA & $3.2003 e+03$ & $3.2003 e+03$ & $6.6178 \mathrm{e}+04$ & $1.8076 \mathrm{e}+04$ & $2.3940 \mathrm{e}+04$ & 15.568 & 36.892 \\
\hline & MVO & 3.9565 & 3.9565 & $4.9374 \mathrm{e}+04$ & $4.3413 e+03$ & $8.5599 \mathrm{e}+03$ & 3.712 & 5.163 \\
\hline & ALO & 6.2254 & 0 & $3.9019 \mathrm{e}+04$ & $2.6497 e+03$ & $5.8941 \mathrm{e}+03$ & 1.254 & 40.886 \\
\hline & MGWO & $2.8399 \mathrm{e}-04$ & $2.8399 \mathrm{e}-4$ & $7.6545 \mathrm{e}+04$ & $1.3452 \mathrm{e}+04$ & $1.8670 \mathrm{e}+04$ & 1.669 & 1.763 \\
\hline & DCSGWO & $2.3764 \mathrm{e}-04$ & $2.3764 \mathrm{e}-04$ & $6.3262 \mathrm{e}+04$ & 767.7876 & $4.4856 \mathrm{e}+03$ & 1.779 & 1.888 \\
\hline & FWAGWO & $1.2829 \mathrm{e}-04$ & $1.2829 \mathrm{e}-04$ & $7.3761 \mathrm{e}+04$ & 751.0181 & $5.0120 \mathrm{e}+03$ & 1.811 & 1.857 \\
\hline & HAGWO & $4.4683 e-18$ & $4.4683 e-37$ & $7.8074 \mathrm{e}+04$ & 658.1758 & $5.5804 \mathrm{e}+03$ & 3.199 & 3.276 \\
\hline & HSSASCA & $1.2220 \mathrm{e}-20$ & 0 & $7.8823 e+04$ & 1.273320 & $9.0073 \mathrm{e}+03$ & 0.483 & 0.515 \\
\hline $\begin{array}{l}\text { Fun. } \\
\text { No. }\end{array}$ & $\begin{array}{c}\text { Algorith } \\
\text { m }\end{array}$ & Best Score & $\begin{array}{c}\text { Min } \\
\text { Value }\end{array}$ & $\begin{array}{c}\text { Max } \\
\text { Value }\end{array}$ & Mean & S.D. & $\begin{array}{c}\text { Self Time } \\
(\mathrm{s})\end{array}$ & $\begin{array}{c}\text { Total Time } \\
\text { (s) }\end{array}$ \\
\hline \multirow[t]{12}{*}{2.} & SSA & 0.0106 & 0 & 17.3558 & 4.3063 & 4.7084 & 0.266 & 0.358 \\
\hline & PSO & $1.2915 \mathrm{e}-06$ & $1.2915 \mathrm{e}-06$ & 92.4274 & 2.2606 & 5.9981 & 0.328 & 0.390 \\
\hline & MFO & $1.1725 \mathrm{e}-05$ & $1.1725 \mathrm{e}-05$ & 472.5344 & 11.2343 & 57.1102 & 0.234 & 0.359 \\
\hline & SCA & $2.3263 e-05$ & 0 & 20.3387 & 2.4146 & 4.6487 & 0.201 & 0.281 \\
\hline & DA & 0.9367 & 0.9367 & 187.2231 & 11.4567 & 29.6896 & 7.884 & 12.793 \\
\hline & MVO & 0.0736 & 0.0736 & 171.9180 & 4.8690 & 11.3572 & 0.685 & 1.014 \\
\hline & ALO & 1.6103 & 0 & 22.9658 & 5.6325 & 6.8939 & 0.516 & 8.550 \\
\hline & MGWO & $6.2826 \mathrm{e}-07$ & $6.2826 \mathrm{e}-07$ & $1.9385 \mathrm{e}+03$ & 6.8720 & 111.9145 & 0.467 & 0.561 \\
\hline & DCSGWO & $1.5601 \mathrm{e}-06$ & $1.5601 \mathrm{e}-06$ & 72.9144 & 0.9138 & 5.1513 & 0.390 & 0.453 \\
\hline & FWAGWO & $1.1151 \mathrm{e}-06$ & $1.1151 \mathrm{e}-06$ & 33.4773 & 0.5179 & 2.7794 & 0.466 & 0.546 \\
\hline & HAGWO & $6.5042 \mathrm{e}-06$ & $6.5042 \mathrm{e}-34$ & $2.2434 \mathrm{e}+03$ & 7.8006 & 129.5365 & 0.858 & 0.983 \\
\hline & HSSASCA & $1.5649 \mathrm{e}-25$ & 0 & 522.6365 & 0.4596 & 2.2949 & 0.125 & 0.187 \\
\hline $\begin{array}{l}\text { Fun. } \\
\text { No. }\end{array}$ & Algorithm & $\begin{array}{l}\text { Best } \\
\text { Score }\end{array}$ & Min Value & $\begin{array}{c}\text { Max } \\
\text { Value }\end{array}$ & Mean & S.D. & $\begin{array}{c}\text { Self Time } \\
\text { (s) }\end{array}$ & $\begin{array}{c}\text { Total Time } \\
\text { (s) }\end{array}$ \\
\hline \multirow[t]{4}{*}{3.} & SSA & 0.0069 & 0 & $5.3657 \mathrm{e}+03$ & 443.0421 & 578.0686 & 0.517 & 1.404 \\
\hline & PSO & $5.3411 \mathrm{e}-04$ & $5.3411 \mathrm{e}-04$ & $1.8194 \mathrm{e}+04$ & 459.8058 & $2.2769 \mathrm{e}+03$ & 0.126 & 0.904 \\
\hline & MFO & 1.0982 & 1.0982 & $1.0448 \mathrm{e}+04$ & $1.7434 \mathrm{e}+03$ & $2.2465 e+03$ & 0.485 & 1.404 \\
\hline & SCA & 0.0035 & 0 & $5.3657 \mathrm{e}+03$ & 443.0421 & 578.0686 & 0.343 & 1.248 \\
\hline
\end{tabular}




\begin{tabular}{|c|c|c|c|c|c|c|c|c|}
\hline & DA & 147.3776 & 147.3776 & $9.1964 e+03$ & $2.3952 \mathrm{e}+03$ & $3.0610 \mathrm{e}+03$ & 12.699 & 23.759 \\
\hline & MVO & 0.3424 & 0.3424 & $2.2581 \mathrm{e}+04$ & 806.4928 & $2.2571 \mathrm{e}+03$ & 0.984 & 1.825 \\
\hline & ALO & 143.0023 & 0 & $7.8399 e+03$ & $1.0820 \mathrm{e}+03$ & $1.7367 e+03$ & 0.419 & 8.487 \\
\hline & MGWO & $4.9523 \mathrm{e}-07$ & $4.9523 \mathrm{e}-07$ & $2.0697 e+04$ & 182.8018 & $1.2946 \mathrm{e}+03$ & 0.765 & 1.622 \\
\hline & DCSGWO & $2.3524 \mathrm{e}-06$ & $2.3524 \mathrm{e}-06$ & $9.4976 \mathrm{e}+03$ & 107.9226 & 683.9416 & 0.668 & 1.170 \\
\hline & FWAGWO & $3.4906 \mathrm{e}-07$ & $3.4906 \mathrm{e}-07$ & $1.4675 \mathrm{e}+04$ & 101.5267 & 912.9078 & 0.673 & 1.388 \\
\hline & HAGWO & $5.8588 \mathrm{e}-14$ & $5.8588 \mathrm{e}-14$ & $1.3787 e+04$ & 271.7098 & $1.3267 e+03$ & 1.638 & 2.216 \\
\hline & HSSASCA & $8.1256 \mathrm{e}-20$ & 0 & $9.7932 \mathrm{e}+04$ & $1.0234 \mathrm{e}+3$ & 951.0627 & 0.299 & 0.717 \\
\hline $\begin{array}{l}\text { Fun. } \\
\text { No. }\end{array}$ & Algorithm & $\begin{array}{c}\text { Best } \\
\text { Score }\end{array}$ & Min Value & $\begin{array}{c}\text { Max } \\
\text { Value }\end{array}$ & Mean & S.D. & $\begin{array}{c}\text { Self Time } \\
\text { (s) }\end{array}$ & $\begin{array}{c}\text { Total Time } \\
\text { (s) }\end{array}$ \\
\hline \multirow[t]{12}{*}{4.} & SSA & $2.3394 \mathrm{e}-04$ & 0 & 38.6947 & 8.3834 & 9.4275 & 0.562 & 0.780 \\
\hline & PSO & 0.0018 & 0.0018 & 73.6156 & 2.9436 & 10.2213 & 0.781 & 0.874 \\
\hline & MFO & 1.7649 & 1.7649 & 59.2316 & 14.1327 & 12.0027 & 0.455 & 0.577 \\
\hline & SCA & 0.0144 & 0 & 68.9919 & 20.7699 & 29.0354 & 0.280 & 0.468 \\
\hline & DA & 1.8577 & 1.8577 & 56.9883 & 14.7945 & 18.7588 & 11.600 & 21.060 \\
\hline & MVO & 0.1512 & 0.1512 & 57.9955 & 6.5487 & 8.0449 & 1.531 & 2.106 \\
\hline & ALO & 1.2354 & 0 & 42.7337 & 7.5733 & 9.1118 & 0.848 & 10.296 \\
\hline & MGWO & 0.0012 & 0.0012 & 55.9351 & 1.3939 & 5.3739 & 0.778 & 1.030 \\
\hline & DCSGWO & 0.0019 & 0.0019 & 69.8150 & 1.6043 & 6.1068 & 0.704 & 0.858 \\
\hline & FWAGWO & $7.7089 \mathrm{e}-04$ & $7.7089 \mathrm{e}-04$ & 69.6581 & 0.9924 & 5.0094 & 0.715 & 0.920 \\
\hline & HAGWO & $7.6393 e-08$ & $7.6393 e-12$ & 62.8402 & 0.9806 & 5.2959 & 1.343 & 1.451 \\
\hline & HSSASCA & $2.5975 \mathrm{e}-17$ & 0 & 76.4551 & 0.5363 & 6.3498 & 0.185 & 0.296 \\
\hline $\begin{array}{l}\text { Fun. } \\
\text { No. }\end{array}$ & Algorithm & $\begin{array}{l}\text { Best } \\
\text { Score }\end{array}$ & Min Value & $\begin{array}{c}\text { Max } \\
\text { Value }\end{array}$ & Mean & S.D. & $\begin{array}{c}\text { Self Time } \\
\text { (s) }\end{array}$ & $\begin{array}{c}\text { Total Time } \\
\text { (s) }\end{array}$ \\
\hline \multirow[t]{12}{*}{5.} & SSA & 8.3157 & 0 & $1.3494 \mathrm{e}+06$ & $1.9852 \mathrm{e}+05$ & $2.8568 \mathrm{e}+05$ & 0.655 & 0.889 \\
\hline & PSO & 5.6829 & 5.6829 & $3.5715 \mathrm{e}+07$ & $1.9152 \mathrm{e}+05$ & $2.2477 \mathrm{e}+06$ & 0.545 & 0.952 \\
\hline & MFO & 21.2357 & 21.2357 & $1.7631 \mathrm{e}+07$ & $8.2866 \mathrm{e}+05$ & $3.0527 e+06$ & 0.639 & 0.795 \\
\hline & SCA & 7.3599 & 0 & $1.3494 \mathrm{e}+06$ & $1.9852 \mathrm{e}+05$ & $2.8568 \mathrm{e}+05$ & 0.531 & 0.686 \\
\hline & DA & 141.9876 & 141.9876 & $5.2798 \mathrm{e}+07$ & $3.0983 \mathrm{e}+06$ & $8.4395 \mathrm{e}+06$ & 13.117 & 23.648 \\
\hline & MVO & $2.1040 \mathrm{e}+03$ & $2.1040 \mathrm{e}+03$ & $1.3201 \mathrm{e}+07$ & $2.2837 \mathrm{e}+05$ & $1.3008 \mathrm{e}+06$ & 1.484 & 2.106 \\
\hline & ALO & 8.7070 & $2.1040 \mathrm{e}+03$ & $1.3201 \mathrm{e}+07$ & $2.2837 e+05$ & $1.3008 \mathrm{e}+06$ & 1.140 & 15.614 \\
\hline & MGWO & 8.9504 & 8.9504 & $2.5173 e+07$ & $9.6965 e+04$ & $1.4602 \mathrm{e}+06$ & 0.842 & 0.967 \\
\hline & DCSGWO & 8.9602 & 8.9602 & $1.7942 \mathrm{e}+07$ & $7.5526 \mathrm{e}+04$ & $1.0570 \mathrm{e}+06$ & 0.953 & 1.123 \\
\hline & FWAGWO & 9.6635 & 9.6635 & $2.8436 \mathrm{e}+07$ & $1.1315 \mathrm{e}+05$ & $1.6614 \mathrm{e}+06$ & 0.845 & 1.014 \\
\hline & HAGWO & 7.2040 & 7.2040 & $3.6735 \mathrm{e}+07$ & $1.8210 \mathrm{e}+05$ & $2.2771 \mathrm{e}+06$ & 1.452 & 1.669 \\
\hline & HSSASCA & 6.8053 & 0 & $5.4183 \mathrm{e}+07$ & $1.3471 \mathrm{e}+04$ & $5.1118 \mathrm{e}+06$ & 0.237 & 0.390 \\
\hline $\begin{array}{l}\text { Fun. } \\
\text { No. }\end{array}$ & Algorithm & $\begin{array}{c}\text { Best } \\
\text { Score } \\
\end{array}$ & Min Value & $\begin{array}{c}\text { Max } \\
\text { Value } \\
\end{array}$ & Mean & S.D. & $\begin{array}{c}\text { Self Time } \\
\text { (s) }\end{array}$ & $\begin{array}{c}\text { Total Time } \\
\text { (s) }\end{array}$ \\
\hline \multirow[t]{12}{*}{6.} & SSA & $7.9154 \mathrm{e}-10$ & 0 & $4.4506 \mathrm{e}+03$ & 746.7452 & 975.7130 & 0.608 & 0.671 \\
\hline & PSO & $4.5756 \mathrm{e}-15$ & $4.5756 \mathrm{e}-15$ & $1.7447 e+04$ & 335.3805 & $1.9012 \mathrm{e}+03$ & 0.672 & 0.733 \\
\hline & MFO & $2.0967 \mathrm{e}-06$ & $2.0967 \mathrm{e}-06$ & $2.0146 \mathrm{e}+04$ & $1.1386 \mathrm{e}+03$ & $3.1252 \mathrm{e}+03$ & 0.563 & 0.671 \\
\hline & SCA & 0.1799 & 0 & $1.9716 \mathrm{e}+04$ & 994.3458 & $2.0959 \mathrm{e}+03$ & 0.499 & 0.577 \\
\hline & DA & 32.3095 & 32.3095 & $5.5216 e+03$ & 988.6377 & $1.6564 \mathrm{e}+03$ & 14.385 & 24.442 \\
\hline & MVO & 0.0417 & 0.0417 & $1.4102 \mathrm{e}+04$ & 391.3245 & $1.3024 \mathrm{e}+03$ & 1.451 & 2.012 \\
\hline & ALO & $3.8248 \mathrm{e}-07$ & 0 & $4.93083+03$ & 201.1074 & 682.6841 & 0.670 & 0.811 \\
\hline & MGWO & 1.0053 & 1.0053 & $1.1956 \mathrm{e}+04$ & 74.7038 & 717.8152 & 1.173 & 14.849 \\
\hline & DCSGWO & 2.0017 & 2.0017 & $1.6848 \mathrm{e}+04$ & 106.0464 & $1.0448 \mathrm{e}+03$ & 0.780 & 0.858 \\
\hline & FWAGWO & 0.2533 & 0.2533 & $1.5178 \mathrm{e}+04$ & 96.9959 & $950 .+6137$ & 0.859 & 0.889 \\
\hline & HAGWO & $3.4225 \mathrm{e}-05$ & $3.4225 \mathrm{e}-05$ & $1.9603 \mathrm{e}+04$ & 141.1776 & $1.3994 \mathrm{e}+03$ & 1.423 & 1.544 \\
\hline & HSSASCA & $1.7573 e-15$ & 0 & $5.6263 \mathrm{e}+04$ & 112.1714 & $1.3203 \mathrm{e}+03$ & 0.141 & 0.281 \\
\hline $\begin{array}{l}\text { Fun. } \\
\text { No. }\end{array}$ & Algorithm & $\begin{array}{l}\text { Best } \\
\text { Score }\end{array}$ & Min Value & $\begin{array}{l}\text { Max } \\
\text { Value }\end{array}$ & Mean & S.D. & $\begin{array}{c}\text { Self Time } \\
\text { (s) }\end{array}$ & $\begin{array}{c}\text { Total Time } \\
\text { (s) }\end{array}$ \\
\hline \multirow[t]{2}{*}{7.} & SSA & 0.0219 & 0 & 0.8737 & 0.0394 & 0.0559 & 0.562 & 0.780 \\
\hline & PSO & 0.0045 & 0.0045 & 9.0468 & 1.1778 & 1.8024 & 0.669 & 0.842 \\
\hline
\end{tabular}


A New Fusion of Salp Swarm with Sine Cosine for Optimization of Non-linear Functions

\begin{tabular}{|c|c|c|c|c|c|c|c|}
\hline MFO & 0.0146 & 0.0146 & 7.0675 & 0.3132 & 1.0587 & 0.485 & 0.609 \\
\hline SCA & 0.0023 & 0 & 3.7177 & 0.3634 & 0.8358 & 0.470 & 0.624 \\
\hline DA & 0.0280 & 0.0280 & 3.0533 & 0.4134 & 0.7881 & 12.300 & 22.905 \\
\hline MVO & 0.0043 & 0.0043 & 7.6655 & 0.1185 & 0.5758 & 1.454 & 1.966 \\
\hline ALO & 0.0719 & 0 & 0.3726 & 0.1204 & 0.0929 & 0.798 & 15.118 \\
\hline MGWO & 0.0041 & 0.0041 & 6.6000 & 0.0323 & 0.3832 & 0.750 & 0.858 \\
\hline DCSGWO & 0.0053 & 0.0053 & 7.4071 & 0.0440 & .4361 & 0.731 & 0.936 \\
\hline FWAGWO & 0.0055 & 0.0055 & 7.0363 & 0.0454 & 0.4123 & 0.841 & 0.936 \\
\hline HAGWO & $9.5054 \mathrm{e}-04$ & $9.5054 \mathrm{e}-04$ & 3.3142 & 0.0244 & 0.2209 & 1.500 & 1.654 \\
\hline HSSASCA & $6.9032 \mathrm{e}-04$ & 0 & 9.7721 & 0.0197 & 0.3771 & 0.218 & 0.327 \\
\hline
\end{tabular}
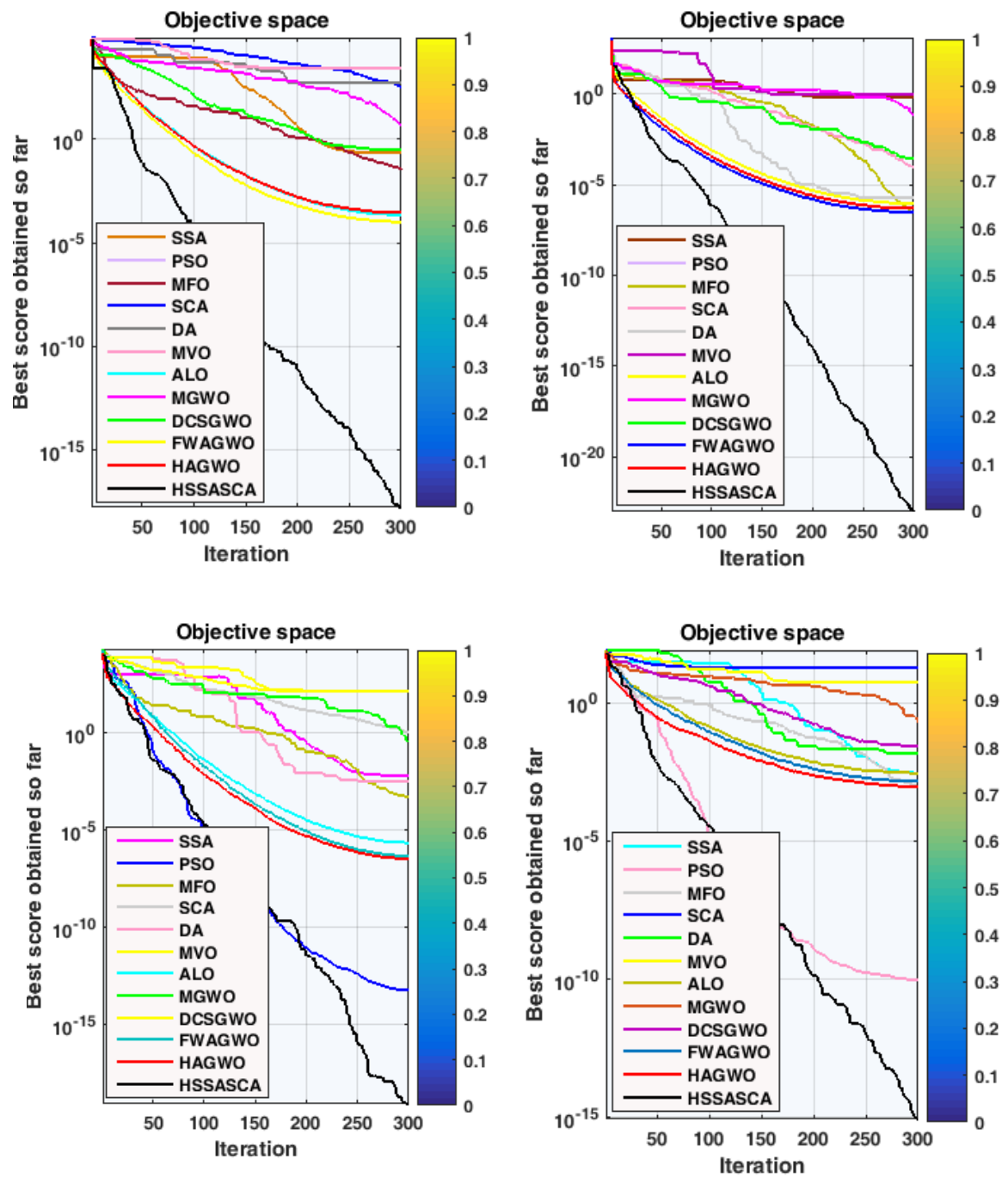

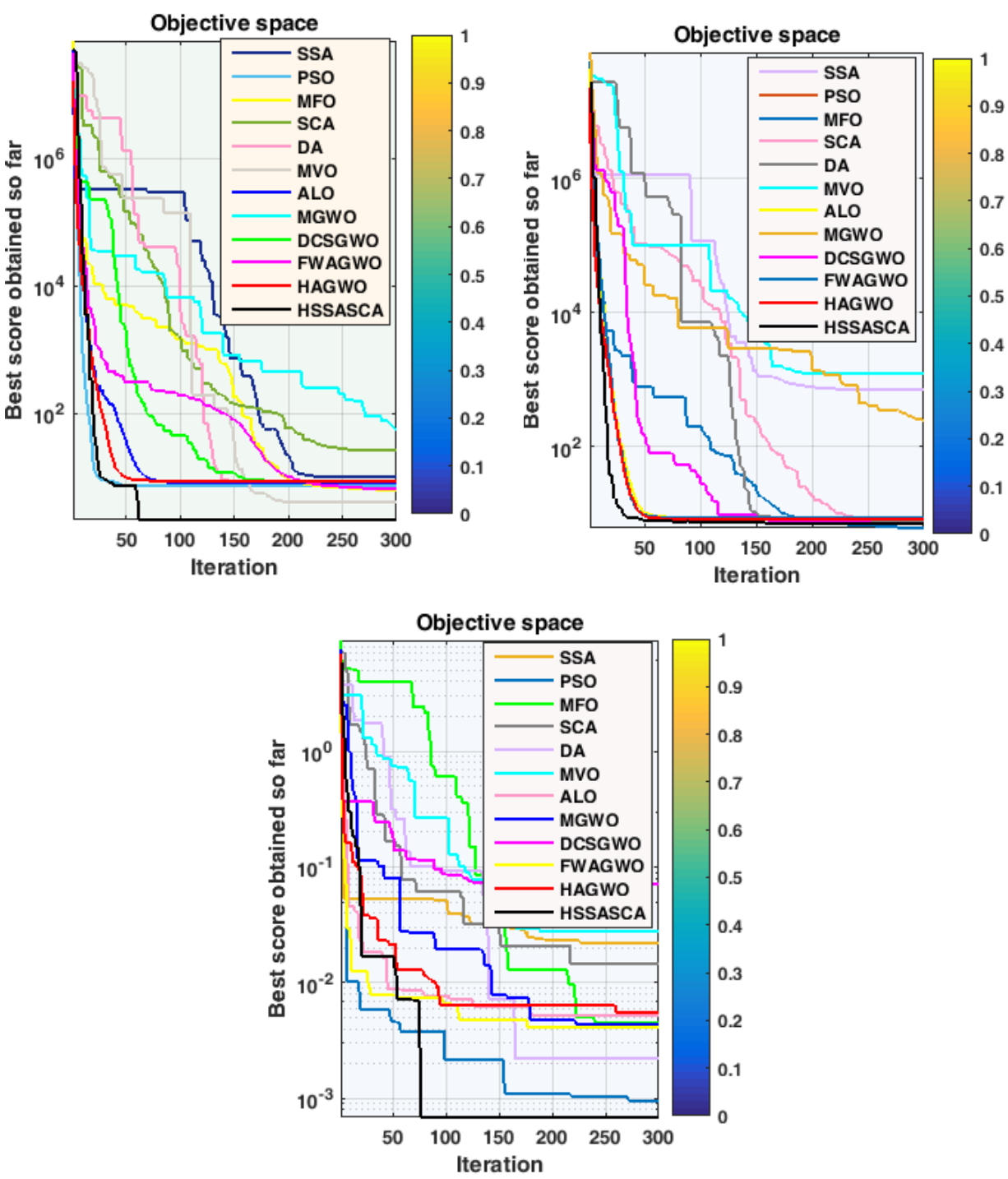

Figures 2. Convergence graphs of algorithms on Uni-modal functions

\subsection{Multi-Modal Test Functions}

The accuracy/or performance of new hybrid method has-been discussed on the multi-modal functions in this subsection and also verifying the ability of the algorithm with others. The experimental results of these functions have been prescribed in Table 3 and Figure 3. The superiority and ability of the proposed variant has been verified in the terms of best scores, average, minimum-and-maximum-objective-function-value, standard-deviation, self and total time on different dimensions. Here we see that, the proposed approach achieves superior quality of numerical solutions on these functions outperforms than others. Moreover, the testing results reveal that the high exploration of the new hybrid method is competent to explore the search space extensively and provide potential areas of the search field. 
A New Fusion of Salp Swarm with Sine Cosine for Optimization of Non-linear Functions

Table 3. Results of SSA, PSO, MFO, SCA, DA, MVO, ALO, MGWO, DCSGWO, FWAGWO, HAGWO and HSSASCA algorithms on six Multi-modal functions at different iterations

\begin{tabular}{|c|c|c|c|c|c|c|c|c|}
\hline $\begin{array}{l}\text { Fun. } \\
\text { No. }\end{array}$ & $\begin{array}{c}\text { Algorith } \\
\text { m }\end{array}$ & Best Score & Min Value & $\begin{array}{c}\text { Max } \\
\text { Value }\end{array}$ & Mean & S.D. & $\begin{array}{c}\text { Self } \\
\text { Time } \\
(\mathbf{s})\end{array}$ & $\begin{array}{c}\text { Total Time } \\
\text { (s) }\end{array}$ \\
\hline \multirow[t]{12}{*}{1.} & SSA & $-2.4116 e+03$ & $-2.4116 \mathrm{e} 03$ & 0 & $-2.0829 e+03$ & 425.4179 & 0.670 & 0.889 \\
\hline & PSO & $-1.8404 e+03$ & $-1.8404 \mathrm{e}+03$ & -997.8602 & $-1.7778 e+03$ & 167.7536 & 0.732 & 0.811 \\
\hline & MFO & $-2.6410 e+03$ & $-2.6410 e+03$ & -897.3669 & $-2.5613 e+03$ & 243.4334 & 0.609 & 0.733 \\
\hline & SCA & $-1.9765 e+03$ & $-1.9765 e+03$ & 0 & $-1.8812 \mathrm{e}+03$ & 133.6997 & 0.515 & 0.639 \\
\hline & DA & $-3.0145 e+03$ & $-3.145 e+03$ & $-1.3349 \mathrm{e}+03$ & $-2.5636 e+03$ & 566.1670 & 10.870 & 21.586 \\
\hline & MVO & $-2.7450 e+03$ & $-2.7450 e+03$ & $-1.4355 \mathrm{e}+03$ & $-2.3753 e+03$ & 361.4196 & 1.327 & 1701 \\
\hline & ALO & $-1.9258 \mathrm{e}+03$ & $-1.9258 \mathrm{e}+03$ & 0 & $-1.9002 e+03$ & 153.8352 & 0.858 & 15.238 \\
\hline & MGWO & $-1.4753 e+03$ & $-1.4753 e+03$ & $-1.4753 e+03$ & $-1.4753 e+03$ & $2.2775 \mathrm{e}-13$ & 0.875 & 0.952 \\
\hline & DCSGWO & $-2.0578 e+03$ & $-2.0578 \mathrm{e}+03$ & $-1.2804 \mathrm{e}+03$ & $-1.9186 e+03$ & 137.3616 & 0.810 & 0.951 \\
\hline & FWAGWO & $-2.1944 e+03$ & $-2.1944 e+03$ & $-1.3215 \mathrm{e}+03$ & $-2.0473 e+03$ & 216.2622 & 0.841 & 0.952 \\
\hline & HAGWO & $-3.0038 \mathrm{e}+03$ & $-3.0038 \mathrm{e}+03$ & $-1.3125 \mathrm{e}+03$ & $-2.9084 e+03$ & 275.5093 & 1.513 & 1.622 \\
\hline & HSSASCA & $-4.1896 e+03$ & $-4.1896 e+03$ & 0 & $-3.9115 e+03$ & 606.3818 & 0.267 & 0.328 \\
\hline $\begin{array}{l}\text { Fun. } \\
\text { No. }\end{array}$ & $\begin{array}{c}\text { Algorith } \\
\text { m }\end{array}$ & Best Score & Min Value & $\begin{array}{c}\text { Max } \\
\text { Value }\end{array}$ & Mean & S.D. & $\begin{array}{c}\text { Self } \\
\text { Time (s) }\end{array}$ & $\begin{array}{c}\text { Total } \\
\text { Time (s) }\end{array}$ \\
\hline \multirow[t]{12}{*}{2.} & SSA & 8.9546 & 0 & 81.7858 & 28.5519 & 19.9196 & 0.654 & 0.889 \\
\hline & PSO & 10.9448 & 10.9448 & 127.4636 & 38.4682 & 26.3051 & 0.593 & 0.749 \\
\hline & MFO & 18.9042 & 18.9042 & 122.8827 & 27.4775 & 20.6718 & 0.574 & 0.718 \\
\hline & SCA & $8.7333 \mathrm{e}-08$ & 0 & 124.1208 & 11.2527 & 26.3977 & 0.532 & 0.702 \\
\hline & DA & 33.8302 & 33.8302 & 134.4354 & 52.2949 & 22.9888 & 11.188 & 20.123 \\
\hline & MVO & 20.9123 & 20.9123 & 127.2166 & 34.9222 & 14.8151 & 1.436 & 1.935 \\
\hline & ALO & 20.8941 & 0 & 107.3150 & 26.6767 & 14.8754 & 1.036 & 14.976 \\
\hline & MGWO & 7.8697 & 7.8697 & 140.1540 & 12.8307 & 12.1917 & 0.922 & 1.077 \\
\hline & DCSGWO & 9.6395 & 9.6395 & 118.3669 & 19.9249 & 13.5677 & 0.872 & 0.998 \\
\hline & FWAGWO & 6.7601 & 6.7601 & 76.7524 & 13.4773 & 13.6135 & 0.967 & 1.061 \\
\hline & HAGWO & 14.2713 & 14.2713 & 91.5892 & 25.4487 & 12.6885 & 1.544 & 1.716 \\
\hline & HSSASCA & 0 & 0 & 159.8672 & 3.8438 & 11.3658 & 0.187 & 0.344 \\
\hline $\begin{array}{l}\text { Fun. } \\
\text { No. }\end{array}$ & $\begin{array}{c}\text { Algorith } \\
\text { m }\end{array}$ & Best Score & Min Value & $\begin{array}{c}\text { Max } \\
\text { Value }\end{array}$ & Mean & S.D. & $\begin{array}{c}\text { Self } \\
\text { Time (s) }\end{array}$ & $\begin{array}{c}\text { Total } \\
\text { Time (s) }\end{array}$ \\
\hline \multirow[t]{12}{*}{3.} & SSA & 1.1551 & 0 & 16.8131 & 6.1739 & 5.2526 & 0.592 & 0.951 \\
\hline & PSO & $5.6659 \mathrm{e}-07$ & $5.6659 \mathrm{e}-07$ & 19.8968 & 2.0283 & 3.0227 & 0.811 & 1.014 \\
\hline & MFO & $1.6335 \mathrm{e}-04$ & $1.6335 \mathrm{e}-04$ & 20.1039 & 3.1792 & 5.3948 & 0.671 & 0.921 \\
\hline & SCA & $7.2574 \mathrm{e}-05$ & 0 & 18.3448 & 4.5073 & 6.9009 & 0.470 & 0.827 \\
\hline & DA & 2.8165 & 2.8165 & 20.2293 & 7.6156 & 6.1782 & 13.477 & 24.025 \\
\hline & MVO & 0.1112 & 0.1112 & 20.2943 & 5.5607 & 3.3157 & 1.569 & 2.309 \\
\hline & ALO & $4.7989 \mathrm{e}-04$ & 0 & 17.1075 & 2.5250 & 4.0269 & 1.051 & 15.304 \\
\hline & MGWO & 3.4251 & 3.4251 & 19.8991 & 3.9145 & 1.7838 & 0.890 & 1.123 \\
\hline & DCSGWO & 3.4093 & 3.4093 & 19.6077 & 3.9133 & 1.8934 & 0.856 & 1.061 \\
\hline & FWAGWO & 3.5745 & 3.5745 & 20.6039 & 3.9387 & 1.6163 & 0.809 & 1.123 \\
\hline & HAGWO & $7.9936 \mathrm{e}-15$ & $7.9936 \mathrm{e}-15$ & 16.7955 & 0.3859 & 2.0401 & 1.437 & 1.685 \\
\hline & HSSASCA & $4.4409 \mathrm{e}-15$ & 0 & 20.8976 & 0.3421 & 1.6766 & 0.234 & 0.453 \\
\hline $\begin{array}{l}\text { Fun. } \\
\text { No. }\end{array}$ & $\begin{array}{c}\text { Algorith } \\
\text { m }\end{array}$ & Best Score & Min Value & $\begin{array}{c}\text { Max } \\
\text { Value }\end{array}$ & Mean & S.D. & $\begin{array}{c}\text { Self } \\
\text { Time (s) }\end{array}$ & $\begin{array}{c}\text { Total } \\
\text { Time (s) }\end{array}$ \\
\hline \multirow[t]{7}{*}{4.} & SSA & 0.2140 & 0 & 44.8338 & 8.6201 & 10.8585 & 0.656 & 0.827 \\
\hline & PSO & 0.0910 & 0.0910 & 118.7388 & 14.6086 & 30.9800 & 0.595 & 0.780 \\
\hline & MFO & 0.5658 & 0.5658 & 159.3326 & 12.6717 & 31.8605 & 0.577 & 0.811 \\
\hline & SCA & 0.3985 & 0 & 127.9587 & 6.6873 & 21.4123 & 0.546 & 0.702 \\
\hline & DA & 0.5188 & 0.5188 & 172.6721 & 18.2751 & 45.0597 & 12.817 & 22.678 \\
\hline & MVO & 0.4759 & 0.4759 & 99.8207 & 4.4026 & 11.9767 & 1.280 & 1.810 \\
\hline & ALO & 0.3320 & 0 & 45.6347 & 3.4729 & 9.0076 & 0.738 & 13.913 \\
\hline
\end{tabular}




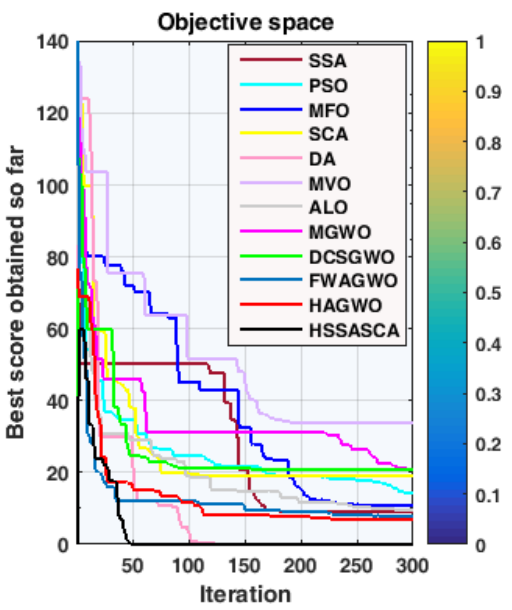



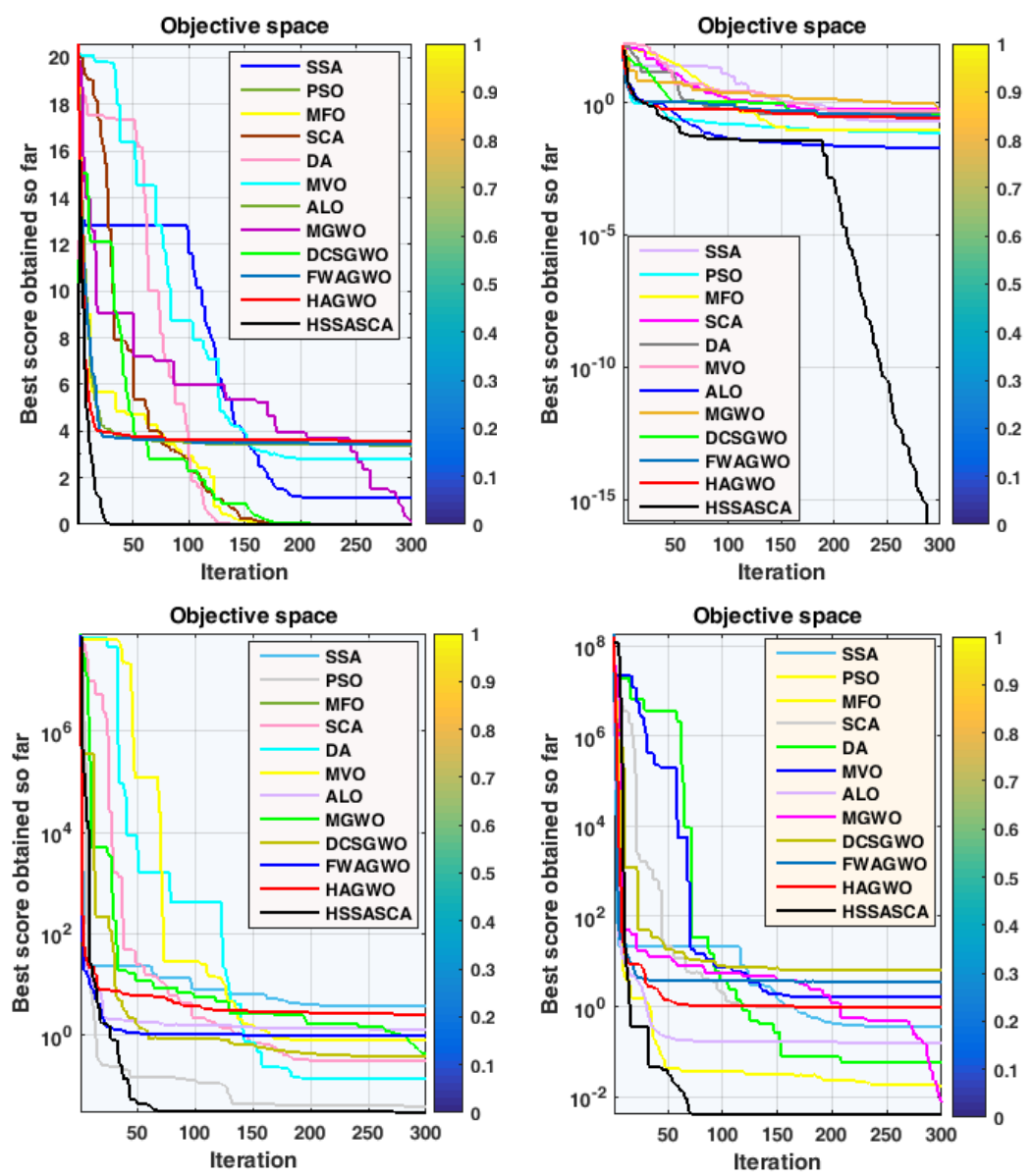

Figure 3. Convergence graphs of algorithms on Multi-modal functions

\subsection{Fixed-Dimension-Multi-Modal-Test-Functions}

In this subsection, we discuss solution of the fixed dimension multimodal functions. All the solutions of metaheuristics have been illustrated in Table 9 and Figure 4. Table 7 reveals that the proposed variant is more competent and reliable to search the best and superior quality of the optimal results in the search area/or space of the functions. These solutions depict that in the modified method has been better characteristics in superior quality of the optimal results and also robustness of the optimal solutions.

\subsection{Exploitation Tendency}

As per experimental solutions of Table 7, Hybrid method is able to found best, possible and very completive solutions of the uni-modal tested problems. This approach outperforms than others in all problems/or functions. It could be noted that the uni-modal problems are more appropriate for-benchmarking exploitation. Hence, these optimal solutions show the better performance of newly method in-terms of exploiting the optimum. This is owing to the planned exploitation operators discussed earlier.

\subsection{Exploration Tendency}

In distinction to the multi-modal and uni-modal tested problems, there are several local optima, whose number is increasing with the dimension. This makes them suitable for testing functions the exploration capability of an metaheuristic. As per solutions of the Table 3 and 4, newly proposed algorithm is competent to find the best, possible and highly competitive solutions, on these test functions/or problems as well. The HSSASCA outperforms SSA, PSO, MFO, SCA, DA, MVO, ALO, MGWO, DCSGWO, FWAGWO and HAGWO on the majority of the tested problems. All statistical solutions reveal that the newly hybrid approach has highly merit in the terms of exploration. 
Table 4. Results of SSA, PSO, MFO, SCA, DA, MVO, ALO, MGWO, DCSGWO, FWAGWO, HAGWO and HSSASCA algorithms on nine fixed dimension multi-modal functions at different iterations 


\begin{tabular}{|c|c|c|c|c|c|c|c|c|}
\hline & SCA & 3.0002 & 0 & 35.2907 & 3.8395 & 3.9662 & 0.280 & 0.328 \\
\hline & DA & 3.0000 & 3.0000 & 180.3669 & 3.8784 & 10.5057 & 10.157 & 14.996 \\
\hline & MVO & 3.0000 & 3.0000 & 13.5599 & 3.3639 & 1.8021 & 0.438 & 0.718 \\
\hline & ALO & 3.0000 & 0 & 220.9587 & 4.1085 & 12.8038 & 0.425 & 3.246 \\
\hline & MGWO & 3.0004 & 3.0006 & 40.2218 & 3.2219 & 2.6586 & 0.326 & 0.374 \\
\hline & DCSGWO & 3.0007 & 3.0009 & 42.3056 & 3.2389 & 2.6805 & 0.313 & 0.328 \\
\hline & FWAGWO & 3.0003 & 3.0000 & 59.3899 & 3.2371 & 3.3222 & 0.328 & 0.359 \\
\hline & HAGWO & 3.0000 & 3.0006 & 80.3246 & 3.2815 & 4.4711 & 0.624 & 0.686 \\
\hline & HSSASCA & 3.0000 & 0 & 199.1416 & 3.0233 & 6.4278 & 0.048 & 0.125 \\
\hline $\begin{array}{l}\text { Fun. } \\
\text { No. }\end{array}$ & Algorithm & $\begin{array}{c}\text { Best } \\
\text { Score }\end{array}$ & $\begin{array}{c}\text { Min } \\
\text { Value }\end{array}$ & $\begin{array}{c}\text { Max } \\
\text { Value }\end{array}$ & Mean & S.D. & $\begin{array}{c}\text { Self } \\
\text { Time } \\
\text { (s) }\end{array}$ & $\begin{array}{c}\text { Total } \\
\text { Time (s) }\end{array}$ \\
\hline \multirow[t]{12}{*}{5.} & SSA & -3.8628 & -3.8628 & 0 & -3.8103 & 0.2302 & 0.484 & 0.702 \\
\hline & PSO & -3.8628 & -3.8628 & -3.6959 & -3.8611 & 0.0102 & 0.389 & 0.670 \\
\hline & MFO & -3.8628 & -3.8628 & -3.4972 & -3.8548 & 0.0478 & 0.391 & 0.702 \\
\hline & SCA & -3.8512 & -3.8512 & 0 & -3.8103 & 0.2302 & 0.372 & 0.561 \\
\hline & DA & -3.8628 & -3.8628 & -3.7891 & -3.8611 & 0.0085 & 9.418 & 14.601 \\
\hline & MVO & -3.8628 & -3.8628 & -3.7774 & -3.8495 & 0.0190 & 0.596 & 1.061 \\
\hline & ALO & -3.8628 & -3.8628 & 0 & -3.8412 & 0.2243 & 0.499 & 4.337 \\
\hline & MGWO & -3.8627 & -3.8627 & -3.7996 & -3.8596 & 0.0059 & 0.404 & 0.671 \\
\hline & DCSGWO & -3.8627 & -3.8627 & -2.9422 & -3.8573 & 0.0546 & 0.373 & 0.639 \\
\hline & FWAGWO & -3.8626 & -3.8626 & -3.4605 & -3.8503 & 0.0338 & 0.406 & 0.655 \\
\hline & HAGWO & -3.8619 & -3.8619 & -2.8640 & -3.8562 & 0.0583 & 0.749 & 1.108 \\
\hline & HSSASCA & -3.8747 & -3.8747 & 0 & -3.8990 & 0.2625 & 0.078 & 0.405 \\
\hline
\end{tabular}



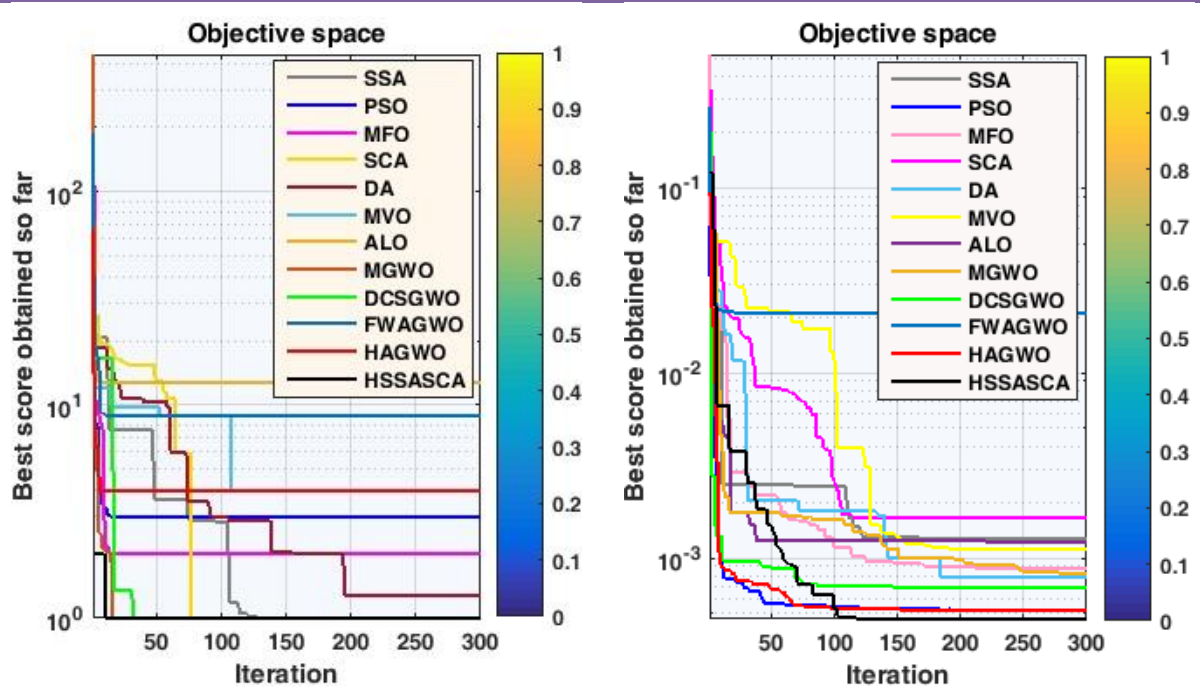

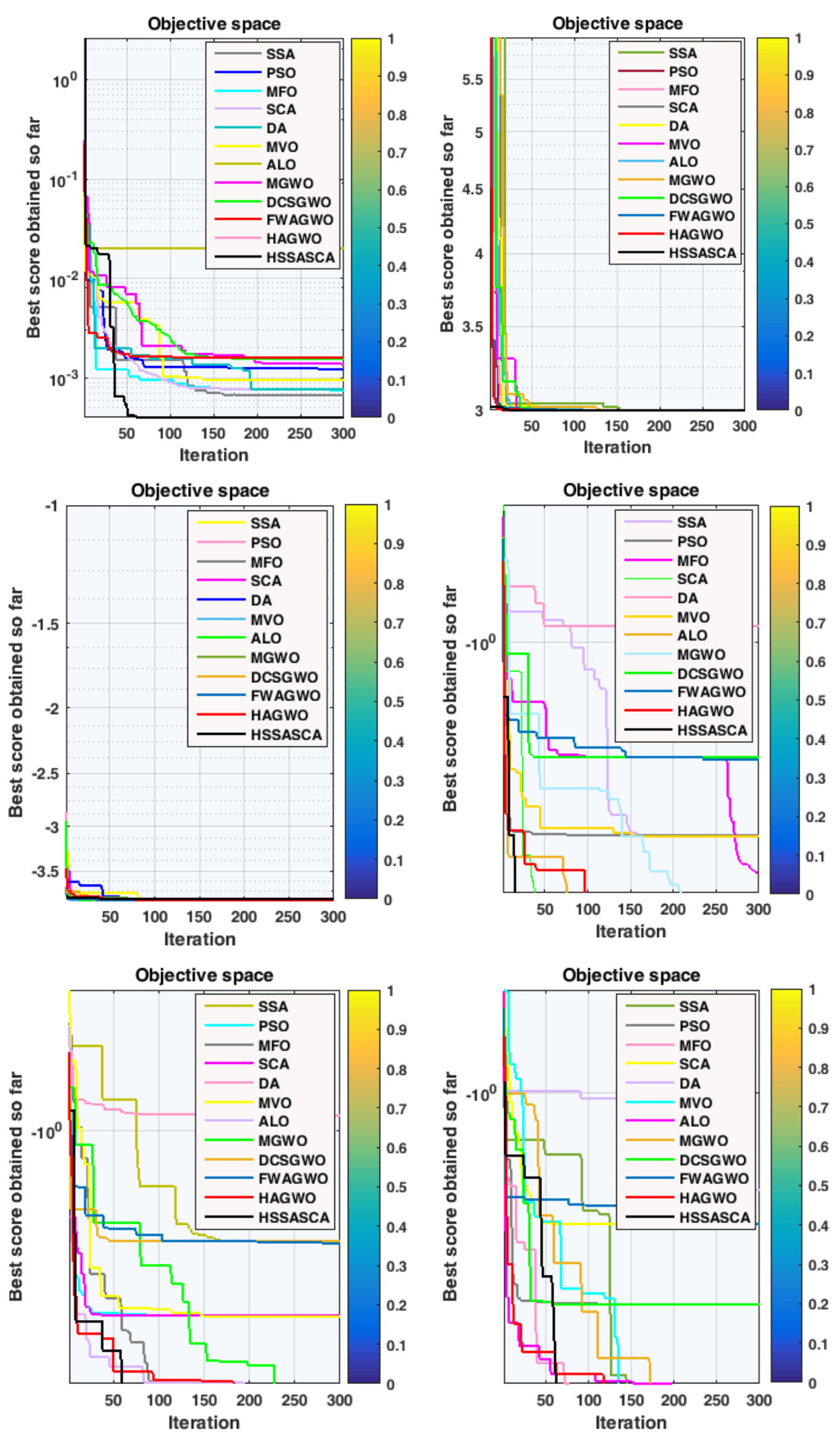


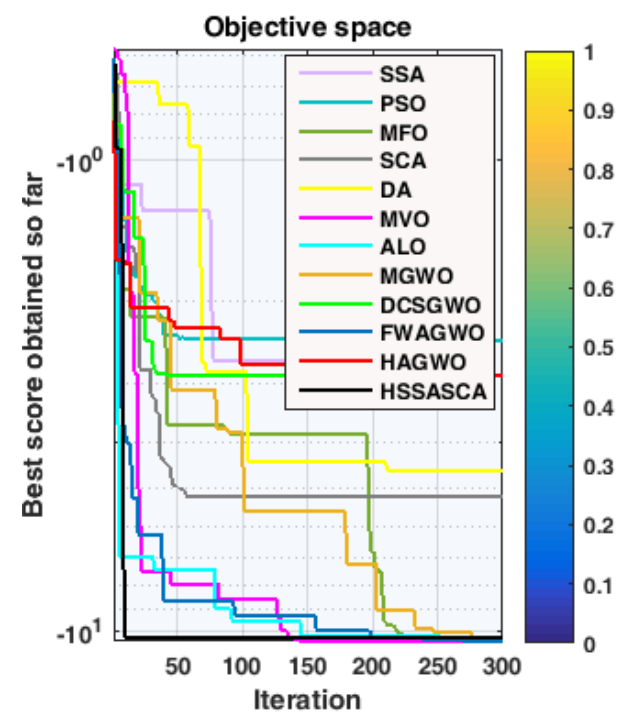

Figure 4. Convergence graphs of algorithms on fixed dimension multi-modal functions

\subsection{Performance Assessment of Hybrid SSASCA}

Concerning the consideration, the performance/or accuracy of the newly method has verified through applying the Wilcoxon signed ranks method for a superior assessment [14]. It is a non-parametric method that is utilized on two different samples, for finding the significance between them. On behalf of significance, we can easily choose the best one sample between them. In addition, the help of this method easily locates the significant difference of the behaviors of two meta-heuristics. The steps are shown as follows:

i. Select the data of two samples $x_{i}$ and $y_{i}$.

ii. Calculate each and every paired difference: $d_{i}=x_{i}-y_{i}$.

iii. $\quad$ Take $\left|d_{i}\right|=\left|x_{i}-y_{i}\right|$.

iv. Rank the $\left|d_{i}\right|$, ignoring the negative sign's (i.e. allot rank-1 to the highest least valve of $\left|d_{i}\right|$ and rank-2 to the next, etc.)

v. Calculate the positive values $\left(\left|d_{i}\right|>0,1,-1\right)$

vi. Find the signed rank of using $\left|d_{i}\right| \times\left(\left|d_{i}\right|>0,1,-1\right)$

vii. Calculate $\sum_{i=1}^{n} R^{+}$and $\sum_{i=1}^{n} R^{-}$the sum of the ranks of the positive and negative, further check the total, $\sum_{i=1}^{n} R^{+}+\sum_{i=1}^{n} R^{-}=\frac{n(n+1)}{2}$, where $n$ is the strength of the sample.

viii. Calculate $W=\max \left(R^{+}, R^{-}\right)$, if two or more differences/observations may be equal, In that case we handle the tied problem by using $\frac{t^{3}-t}{48}$, where $t \sim$ is a total number of tied.

ix. Use normal approximation and calculate $\mu_{W}=\frac{n(n+1)}{4}, \sigma_{W}=\sqrt{\frac{n(n+1)(2 n+1)}{24}}$ and we get

$$
z=\max \left(R^{+}, R^{-}\right)-\mu_{W} / \sqrt{\frac{n(n+1)(2 n+1)}{24}-\frac{t^{3}-t}{48}}
$$

x. Finally find out the p-value by using the value of $\mathrm{z}$. 
Here, these steps give the $\mathrm{p}$-value after using the $\mathrm{z}$-value. Here if $p<0.05$, then it represents a rejection of the $H_{0}$ hypothesis, whereas $p>0.05$ represents a failure to reject the null hypothesis. Hence p-values are less than 0.05 , it can be determined that HSSASCA is significantly superior to the other optimizer. If not, the obtained improvements are not statistically significant. The obtained p-values are presented in Tables 8-10.

Table 5. Results of the median values of the meta-heuristics on uni-modal functions

\begin{tabular}{|c|c|c|c|c|c|c|c|c|c|}
\hline \multirow[t]{2}{*}{$\begin{array}{c}\text { Benchmar } \\
\mathbf{k} \\
\text { functions }\end{array}$} & $\begin{array}{c}\text { HSSA } \\
\text { SCA }\end{array}$ & SSA & PSO & \multicolumn{2}{|c|}{ MFO } & SCA & DA & MVO & ALO \\
\hline & $A_{i}$ & $B_{i}$ & $C_{i}$ & \multicolumn{2}{|c|}{$D_{i}$} & $E_{i}$ & $F_{i}$ & $G_{i}$ & $H_{i}$ \\
\hline 1. & 25.0237 & $\begin{array}{c}2.5703 \mathrm{e}+0 \\
3\end{array}$ & $\begin{array}{c}114.294 \\
9\end{array}$ & \multicolumn{2}{|c|}{$\begin{array}{c}1.7984 \mathrm{e}+0 \\
4\end{array}$} & $\begin{array}{c}2.3657 \mathrm{e}+0 \\
4\end{array}$ & $\begin{array}{c}2.9852 \mathrm{e}+0 \\
3\end{array}$ & $\begin{array}{c}1.5149 \mathrm{e}+0 \\
3\end{array}$ & $\begin{array}{c}4.1311 \mathrm{e}+0 \\
3\end{array}$ \\
\hline 2. & 0.0021 & 3.5665 & 2.9704 & \multicolumn{2}{|c|}{8.4573} & 0.7450 & 3.3260 & 2.7573 & 2.0038 \\
\hline 3. & 0.2966 & 163.1911 & 15.3970 & \multicolumn{2}{|c|}{428.8130} & $\begin{array}{c}1.8709 \mathrm{e}+0 \\
3\end{array}$ & $\begin{array}{c}2.3374 \mathrm{e}+0 \\
3\end{array}$ & 67.6860 & 370.9822 \\
\hline 4. & 0.0051 & 3.8484 & 0.7070 & \multicolumn{2}{|c|}{23.5791} & 40.7947 & 30.4155 & 5.7345 & 3.6395 \\
\hline 5. & 8.9537 & 485.4100 & $\begin{array}{c}150.539 \\
5 \\
\end{array}$ & \multicolumn{2}{|c|}{$\begin{array}{c}2.0845 e+0 \\
4\end{array}$} & $2.4126 \mathrm{e} 05$ & $\begin{array}{c}3.2456 \mathrm{e}+0 \\
4\end{array}$ & $\begin{array}{c}3.3311 \mathrm{e}+0 \\
3\end{array}$ & 273.0672 \\
\hline 6. & 0.8525 & 38.9567 & 0.6935 & \multicolumn{2}{|c|}{490.7669} & 103.2815 & $\begin{array}{c}1.9025 \mathrm{e}+0 \\
3\end{array}$ & 115.8474 & 266.6742 \\
\hline \multirow[t]{10}{*}{7.} & 0.0013 & 0.0122 & 1.3338 & \multicolumn{2}{|c|}{0.2139} & 0.0292 & 0.0768 & 0.0137 & 0.1274 \\
\hline & & MGWO & DCS & GWO & & NAGWO & HAGWO & & \\
\hline & & $I_{i}$ & \multicolumn{2}{|c|}{$J_{i}$} & & $K_{i}$ & $L_{i}$ & & \\
\hline & & 0.0164 & \multirow{2}{*}{\multicolumn{2}{|c|}{$\begin{array}{c}0.0144 \\
6.0572 \mathrm{e}-05\end{array}$}} & & $1721 \mathrm{e}-21$ & $3.6892 \mathrm{e}-21$ & & \\
\hline & & $2.51149 \mathrm{e}-05$ & & & & $8253 e-21$ & $5.3105 e-21$ & & \\
\hline & & $2.1497 e-04$ & \multicolumn{2}{|c|}{$6.9505 e-04$} & & $8811 \mathrm{e}-09$ & $3.6718 \mathrm{e}-09$ & & \\
\hline & & 0.0099 & \multicolumn{2}{|c|}{0.0169} & & $8890 \mathrm{e}-10$ & $2.3853 \mathrm{e}-10$ & & \\
\hline & & 188.9512 & \multicolumn{2}{|c|}{8.9608} & & 8.5523 & 7.2447 & & \\
\hline & & 1.0130 & \multirow{2}{*}{\multicolumn{2}{|c|}{$\begin{array}{l}2.0044 \\
0.0062\end{array}$}} & & 0.0310 & 0.0249 & & \\
\hline & & 0.0048 & & & & 0.0045 & 0.0022 & & \\
\hline
\end{tabular}

Table 6. Results of the median values of the meta-heuristics on multi-modal functions

\begin{tabular}{||c|c|c|c|c|c|c|c|c|}
\hline \multicolumn{1}{|l}{$\begin{array}{l}\text { Benchmar } \\
\text { k } \\
\text { functions }\end{array}$} & $\begin{array}{c}\text { HSSASC } \\
\text { A }\end{array}$ & SSA & PSO & MFO & SCA & DA & MVO & ALO \\
\hline & $A_{i}$ & $B_{i}$ & $C_{i}$ & $D_{i}$ & $E_{i}$ & $F_{i}$ & $G_{i}$ & $H_{i}$ \\
\hline $\mathbf{1 .}$ & - & - & - & - & - & - & - & - \\
& $3.4018 \mathrm{e}+03$ & $2.6326 \mathrm{e}+0$ & $2.0588 \mathrm{e}+0$ & $2.9877 \mathrm{e}+0$ & $2.0790 \mathrm{e}+0$ & $\begin{array}{c}2.6500 \mathrm{e}+0 \\
3\end{array}$ & $\begin{array}{c}2.5711 \mathrm{e}+0 \\
3\end{array}$ & $\begin{array}{c}2.4516 \mathrm{e}+0 \\
3\end{array}$ \\
\hline $\mathbf{2 .}$ & 35.3485 & 35.0121 & 36.8090 & 59.8340 & 35.0813 & 78.9501 & 34.2582 & 11.5555 \\
\hline $\mathbf{3 .}$ & 0.0034 & 3.8557 & 3.9293 & 10.7276 & 0.3835 & 9.8998 & 5.8717 & 3.1587 \\
\hline $\mathbf{4 .}$ & 0.3222 & 1.3386 & 16.5049 & 3.4179 & 1.2529 & 2.5839 & 2.4355 & 0.7592 \\
\hline $\mathbf{5 .}$ & 0.0906 & 6.2432 & 8.2092 & 9.1456 & 2.5472 & 17.2437 & 3.5896 & 7.4915 \\
\hline $\mathbf{6 .}$ & 0.2277 & 3.9453 & 10.4227 & $2.5091 \mathrm{e}+0$ & 4.1417 & 4.4351 & 5.6141 & 17.0240 \\
\hline
\end{tabular}




\begin{tabular}{|c|c|c|c|}
\hline$I_{i}$ & $J_{i}$ & $K_{i}$ & $L_{i}$ \\
\hline$-1.4753 \mathrm{e}+03$ & $-1.9437 \mathrm{e}+03$ & $-2.0941 \mathrm{e}+03$ & $-2.9867 \mathrm{e}+03$ \\
\hline 99.6272 & 104.9259 & 68.4197 & 71.7602 \\
\hline 3.5123 & 3.4430 & 3.6518 & $7.9936 \mathrm{e}-15$ \\
\hline 95.7587 & 137.9988 & 142.6935 & 137.0655 \\
\hline 1.0071 & 1.4176 & 2.8629 & 0.0434 \\
\hline 1.2595 & $7.0615 \mathrm{e}+07$ & $2.5434 \mathrm{e}+08$ & $1.1278 \mathrm{e}+08$ \\
\hline
\end{tabular}

Table 7. Results of the median values of the meta-heuristics on fixed dimension multi-modal functions

\begin{tabular}{|c|c|c|c|c|c|c|c|c|}
\hline $\begin{array}{l}\text { Benchmark } \\
\text { functions }\end{array}$ & $\begin{array}{c}\text { HSSASC } \\
\text { A }\end{array}$ & SSA & PSO & MFO & SCA & DA & MVO & ALO \\
\hline & $A_{i}$ & $B_{i}$ & $C_{i}$ & $D_{i}$ & $E_{i}$ & $F_{i}$ & $G_{i}$ & $H_{i}$ \\
\hline 1. & 12.6705 & 0.9821 & 1.9920 & 0.9980 & 2.0276 & 0.9983 & 0.9980 & 12.6705 \\
\hline 2. & $\begin{array}{l}7.8992 \mathrm{e}- \\
04\end{array}$ & 0.0257 & 0.0013 & 0.0022 & $\begin{array}{c}9.1590 \mathrm{e}- \\
04\end{array}$ & 4.0039 & $\begin{array}{c}7.9026 \mathrm{e}- \\
04\end{array}$ & 0.0088 \\
\hline 3. & -1.0300 & -1.0250 & -1.0316 & -1.0316 & -1.0284 & -1.0297 & -1.0294 & -1.0316 \\
\hline 4. & 3.0529 & 3.0201 & 3.0022 & 3.0000 & 3.0174 & 3.0128 & 3.0018 & 3.0001 \\
\hline 5. & -3.7823 & -3.8540 & -3.8626 & -3.8628 & -3.8301 & -7.8427 & -8.8557 & -3.8628 \\
\hline 6. & -3.0889 & -3.1547 & -3.2250 & -3.2026 & -2.8229 & -8.9627 & -8.2420 & -3.3217 \\
\hline 7. & -2.3183 & -5.4771 & -9.1597 & -5.0251 & -0.8898 & -11.1008 & -9.1150 & -5.0502 \\
\hline 8. & -6.5662 & -10.6754 & -6.0874 & -3.7210 & -2.0809 & -9.7860 & -6.7621 & -10.3705 \\
\hline 9. & -2.2071 & -6.7476 & -3.7724 & -2.8710 & -0.9363 & -8.3825 & -2.8710 & -10.5186 \\
\hline & \multicolumn{2}{|r|}{ MGWO } & DCSGWO & \multicolumn{2}{|c|}{ FWAGWO } & HAGWO & & \\
\hline & \multicolumn{2}{|r|}{$I_{i}$} & $J_{i}$ & \multicolumn{2}{|c|}{$K_{i}$} & $L_{i}$ & & \\
\hline & \multicolumn{2}{|r|}{8.8408} & 12.6705 & \multicolumn{2}{|c|}{3.9683} & 2.9821 & & \\
\hline & \multicolumn{2}{|r|}{$4.6689 \mathrm{e}-04$} & 0.0204 & \multicolumn{2}{|c|}{0.0073} & $3.2167 \mathrm{e}-04$ & & \\
\hline & \multicolumn{2}{|r|}{-1.0316} & -1.0316 & \multicolumn{2}{|c|}{-1.0316} & -1.0316 & & \\
\hline & \multicolumn{2}{|r|}{3.0013} & 3.0019 & \multicolumn{2}{|c|}{3.0000} & 3.0018 & & \\
\hline & & -3.8604 & -3.8624 & & 624 & -3.8619 & & \\
\hline & & -3.1494 & -3.3174 & & 740 & -3.3006 & & \\
\hline & & -7.6340 & -9.0251 & & 404 & -8.0504 & & \\
\hline & & -9.5044 & -9.2157 & & 197 & -7.0860 & & \\
\hline
\end{tabular}

Table 8. Wilcoxon test for comparison results in Table 5

\begin{tabular}{|c|c|c|c|c|c|c|c|c|}
\hline \multicolumn{2}{|c|}{ Compared Techniques } & \multicolumn{7}{|c|}{ Solution Evaluations } \\
\hline $\begin{array}{c}\text { Proposed } \\
\text { variant }\end{array}$ & $\begin{array}{c}\text { Compared } \\
\text { variant }\end{array}$ & $\begin{array}{c}\begin{array}{c}\text { Sum of } \\
\text { rank }\end{array} \\
\left(\sum_{i=1}^{7} R_{i}^{-}\right)\end{array}$ & $\begin{array}{c}\begin{array}{c}\text { Sum of } \\
\text { rank }\end{array} \\
\left(\sum_{i=1}^{7} R_{i}^{+}\right)\end{array}$ & $\begin{array}{c}\text { Difference } \\
\text { (D) }\end{array}$ & $\begin{array}{c}\text { z- } \\
\text { value }\end{array}$ & $\begin{array}{c}p- \\
\text { value }\end{array}$ & $\begin{array}{c}\text { Accept } \\
(p<0.05) \\
H_{1}\end{array}$ & $\begin{array}{c}\text { Reject } \\
(p<0.05) \\
H_{0}\end{array}$ \\
\hline \multirow{11}{*}{ HSSASCA } & SSA & 28 & 0 & \multirow{11}{*}{$\begin{array}{c}A_{i}-B_{i} \text { to } \\
L_{i}\end{array}$} & 2.366432 & 0.0180 & yes & Yes \\
\hline & PSO & 27 & 1 & & 2.197401 & 0.0280 & yes & Yes \\
\hline & MFO & 28 & 0 & & 2.366432 & 0.0180 & yes & Yes \\
\hline & SCA & 28 & 0 & & 2.366432 & 0.0180 & yes & Yes \\
\hline & DA & 28 & 0 & & 2.366432 & 0.0180 & yes & Yes \\
\hline & MVO & 28 & 0 & & 2.366432 & 0.0180 & yes & Yes \\
\hline & ALO & 28 & 0 & & 2.366432 & 0.0180 & yes & Yes \\
\hline & MGWO & 16 & 12 & & 0.338062 & 0.735363 & no & no \\
\hline & DCSGWO & 15 & 13 & & 0.169031 & 0.865797 & no & no \\
\hline & FWAGWO & 0 & 26 & & -2.02837 & 0.02802 & yes & yes \\
\hline & HAGWO & 1 & 27 & & -2.1974 & 0.02802 & yes & yes \\
\hline
\end{tabular}


Table 10. Wilcoxon test for comparison results in Table 7

\begin{tabular}{|c|c|c|c|c|c|c|c|c|}
\hline \multicolumn{2}{|c|}{ Compared Techniques } & \multicolumn{7}{|c|}{ Solution Evaluations } \\
\hline $\begin{array}{c}\text { Proposed } \\
\text { variant }\end{array}$ & $\begin{array}{c}\text { Compared } \\
\text { variant }\end{array}$ & $\begin{array}{c}\text { Sum of } \\
\text { rank } \\
\left(\sum_{i=1}^{9} R_{i}^{-}\right)\end{array}$ & $\left.\begin{array}{c}\text { Sum of } \\
\text { rank }\end{array}\right)$ & $\begin{array}{c}\text { Difference } \\
\text { (D) }\end{array}$ & $\begin{array}{c}\text { z- } \\
\text { value }\end{array}$ & $\begin{array}{c}\text { p- } \\
\text { value }\end{array}$ & $\begin{array}{c}\text { Accept } \\
(p<0.05) \\
H_{1}\end{array}$ & $\begin{array}{c}\text { Reject } \\
(p<0.05) \\
H_{0}\end{array}$ \\
\hline \multirow{11}{*}{ HSSASCA } & SSA & 3 & 42 & \multirow{11}{*}{$\begin{array}{c}A_{i}-B_{i} \text { to } \\
L_{i}\end{array}$} & 2.310161 & 0.0209 & yes & yes \\
\hline & PSO & 7 & 38 & & 1.836282 & 0.0663 & no & no \\
\hline & MFO & 9 & 36 & & 1.599342 & 0.1097 & no & no \\
\hline & SCA & 29 & 16 & & -0.77005 & 0.4413 & no & no \\
\hline & DA & 5 & 40 & & 2.073221 & 0.0382 & yes & yes \\
\hline & MVO & 3 & 42 & & 2.310161 & 0.0209 & yes & yes \\
\hline & ALO & 4 & 41 & & 2.191691 & 0.0284 & yes & yes \\
\hline & MGWO & 0 & 45 & & 2.66557 & 0.007687 & yes & yes \\
\hline & DCSGWO & 4 & 41 & & 2.191691 & 0.028408 & yes & yes \\
\hline & FWAGWO & 2 & 43 & & 2.42863 & 0.015157 & yes & yes \\
\hline & HAGWO & 0 & 45 & & 2.66557 & 0.007687 & yes & yes \\
\hline
\end{tabular}

Hence, we implement the Wilcoxon test for the newly hybrid method against the several meta-heuristics that appears in Tables 5-7 and the obtained statistical solutions for Wilcoxon test is represented in Table 8-10. On this basis of these statistical results, it is realized that the HSSASCA method has better characteristics such that superiority of the optimal solution and strength of the global optima goal. Also, significant importance may be placed in local exploitation and global exploration. Results illustrate based on Wilcoxon test proved the better performance/or accuracy of the newly method among-others-in-comparison. Hence, the-obtained solutions by the HSSASCA method are-statistically superior and this has not happened by likelihood/or chance.

The convergence performance of Hybrid HSSASCA and comparative algorithms has been verified on basis of statistical and numerical results of uni-modal, multi-modal, fixed dimension multi-modal and constrained engineering functions in this section. The major motivation of the superior accuracy and working performance of the newly hybrid method lies after the optimal result create strategy induced by integrating the important SSA phase with SCA phase. In the presented method, the position of the each salp swarm in the entire group is improved by applying the position equations of sine and cosine; hence the superior optimal solutions have been tried to update based on the sine or cosine function, which means that the exploration ability/or capability can be even more powerful. Indeed, in HSSASCA algorithm, the sine and cosine phase of the SCA algorithm can helps SSA algorithm to find the superior optima value in the search space more rapidly and also refine the working accuracy/or performance and enhance convergence rate. During this research methodology, it certifies that the internal quality of 
this development is regulated to include the SCA as a local research strategy that accelerates the behavior of the transformation and without any amendments in the results of meta-heuristic avoids the systematic. The HSSASCA approach has proven its own significant accuracy during the search procedure, and also reduced the immature convergence inaccuracies of the SSA algorithm by using SCA phase. About the offered analytics, it certifies that the internal quality of this development is regulated to include the SCA as a local research strategy that accelerates convergence behavior, and ignores the meta-heuristics routine tour without any modifications in the results. Thus, there is an important precision and performance in the proposed HSSASCA algorithm and the inefficiency of the inaccessible transition of SSA approach is reduced powerfully.

Further, in order to do a fair comparison of a proposed algorithm with standard PSO, SSA, MFO, SCA, DA MVO, ALO, MGWO, DCSGWO, FWAGWO and HAGWO algorithms, mean and standard deviation for multiple runs have been reported. Here, a least statistic value indicates that the proposed algorithm is more robust, is capable to reproduce the solution with minimum discrepancy and has less dependency on initial population as comparison to other comparative approaches. In the assessment with other meta-heuristics, it seems that the new method performed more significantly. Further, the ability and capability of the proposed algorithm has been verified on the basis of taking a least time during searching of the optimal values in the search space of the functions. Results indicate that the proposed algorithm take a least time during searching the best and possible optimal solution of the problems outperforms than others. Hence, it can be concluded that the proposed algorithm is competent for searching the best optimal solution in the least time.

For testing the convergence performance of the algorithms such as PSO, SSA, MFO, SCA, DA MVO, ALO, MGWO, DCSGWO, FWAGWO, HAGWO and HSSASCA have been plotted the graphs with respect to number of iterations. In the graphs, $x$-axis represents the number of iterations and $y$-axis represents the best score obtained so far. Black line represents the performance of the proposed algorithm and on the basis of others colors we identifies the performance of rest of the algorithms. In these graphs, it can be easily seen that the proposed algorithm takes least time for convergence and search the best optimal solution in the least number of iterations as comparison to others. All the convergence graphs, numerical and statistical solutions of the proposed version assert that it is competent to improving the strength, accuracy, exploration, exploitation in dimensionality reduction tasks and reducing the complexity time of the standard versions. We trust that sine cosine algorithm helps to overcome the drawback of salp swarm.

To summarize, all experimental solutions reveal that the new hybrid method is more supportive in improving the competence of the standalone algorithms in the terms of global optimal result/or solution worth as well as computational efforts. Lastly, we expect that this method will motivate scientists and researchers in meta-heuristics and global optimization areas.

\section{APPLICATIONS}

\subsection{Three-bar Truss Design}

In this section, we apply the proposed method to-solve the three-bar-truss-design-function/or problem [26]. The main aim of this function is to achieve the minimum weight subjected to buck constraints, stress and deflection (see figure 5). The pseudo code of newly method has been run for searching the completive or best solution of this function on the setting of parameters mentioned in section 4. Three-bur truss design function has been solved by HSSASCA and compared with recent comparative algorithms. The mathematical explanation of this function has been described as following:

$$
\begin{gathered}
\text { Minimize } f(x)=\left(2 \sqrt{2} x_{1}+x_{2}\right) * r \\
\text { Subject to } \quad l_{1}(x)=\left(\frac{\sqrt{2} x_{1}+x_{2}}{\sqrt{2} x_{1}^{2}+2 x_{1} x_{2}}\right) \times P-d \leq 0
\end{gathered}
$$


where

$$
\begin{aligned}
& l_{2}(x)=\left(\frac{x_{2}}{\sqrt{2} x_{1}^{2}+2 x_{1} x_{2}}\right) \times P-d \leq 0 \\
& l_{3}(x)=\left(\frac{1}{\sqrt{2} x_{2}+2 x_{1} x_{2}}\right) \times P-d \leq 0
\end{aligned}
$$

$$
0 \leq x_{1}, x_{2} \leq 1, r=100 \mathrm{~cm}, M=2 K N / \mathrm{cm}^{2} \text { and } d=2 K N / \mathrm{cm}^{2}
$$

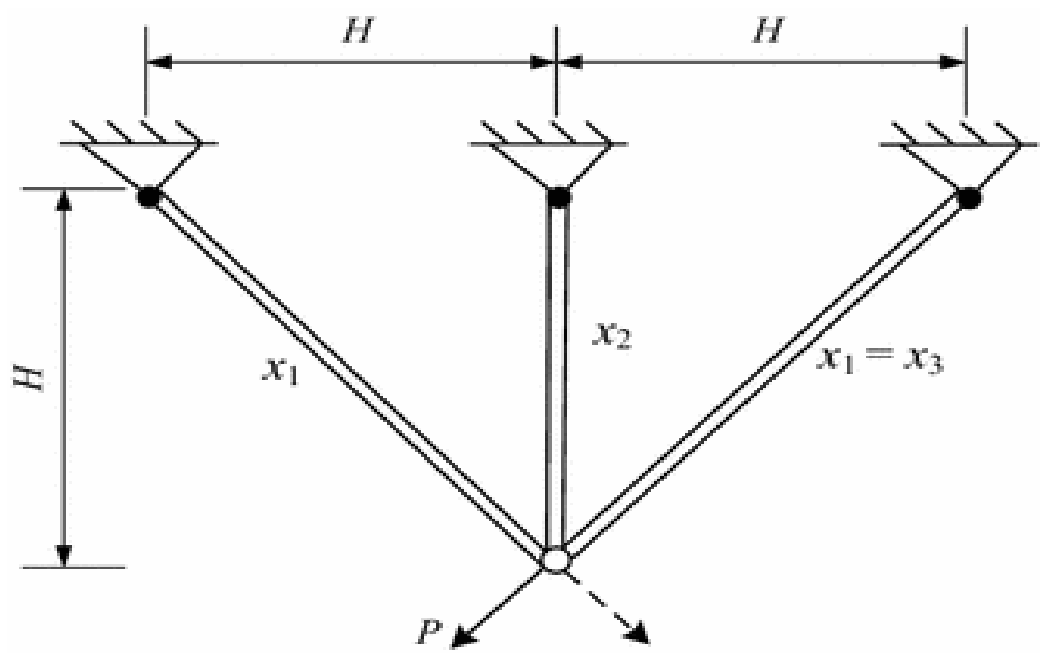

Figure 5.The three-bar truss design problem

Table 11. Best solutions of the three-bar truss design by different algorithms

\begin{tabular}{cccc}
\hline Algorithm & $x_{1}$ & $x_{2}$ & $f(x)$ \\
\hline CS & 0.78867 & 0.40902 & 263.9716 \\
DEDS & 0.78867513 & $0 . .40824828$ & 263.8958434 \\
SC & 0.7886210370 & 0.4084013340 & 263.8958466 \\
MBA & 0.7885650 & 0.4085597 & 263.8958522 \\
MFO & 0.788244770931922 & 0.409466905784741 & 263.895979682 \\
PSO-DE & 0.7886751 & 0.4082482 & 263.8958433 \\
LSA-SM & 0.7886136 & 0.4084224 & 263.8958 \\
HSSASCA & $\mathbf{0 . 7 8 8 5 9 2 3}$ & $\mathbf{0 . 4 0 8 3 2 5 6}$ & $\mathbf{2 6 3 . 8 8 0 1 4 5 1 5 8 5 9 8 5}$ \\
\hline
\end{tabular}

The obtained results of the algorithms have been described in Table 11 including the comparison between the proposed algorithm and others namely Cuckoo search algorithm (CS) [19], Differential-evolution-with-dynamicstochastic-selection-(DEDS) [60], Society and civilization (CS) [40], Mine blast algorithm (MBA) [41], Moth Flame Optimizer (MFO) [33], Hybridizingparticleswarmoptimizationwithdifferentialevolution(PSO-DE) [24] and lightning search algorithm-simplex method (LSA-SM) [26]. Here, it-can-be easily seen that the newly method provides the minimum value (263.8801451585985) of the objective function of this problem in comparison to those of the others. Hence, it can be concluded that the HSSASCA is highly competent for this function than others.

\subsection{Tension/Compression-Spring-Design}

The Tension-Spring-Design-function/or Problem [26] has been solved in this section. The origin motive of this function is to reduce the weight of tension spring design. The pseudo code of newly method has been run for searching the completive or best solution of this function on the setting of parameters mentioned in section 4 . A 
graphic view of Tension/Compression Spring design is shown in figure 6. The proposed algorithm and several comparative algorithms in the literatures have been applied for searching the best global optima result/or solution of this function. The mathematical formulas involved are as follows:

$$
\begin{aligned}
& \text { Minimize } f(x)=\left(x_{3}+2\right) x_{2} x_{1}^{2} \\
& \text { Subject to: minimumdeflection: }\left(m_{1}(x)\right)=1-\frac{x_{2}^{3} x_{3}}{71,785 x_{1}^{4}} \leq 0 \\
& \text { shear stress }\left(m_{2}(x)\right)=\frac{4 x_{2}^{2}-x_{1} x_{2}}{12,566\left(x_{2} x_{1}^{3}-x_{1}^{4}\right)}+\frac{1}{5108 x_{1}^{2}}-1 \leq 0 \\
& \text { shear stress }\left(m_{2}(x)\right)=\frac{4 x_{2}^{2}-x_{1} x_{2}}{12,566\left(x_{2} x_{1}^{3}-x_{1}^{4}\right)}+\frac{1}{5108 x_{1}^{2}}-1 \leq 0
\end{aligned}
$$

$$
\text { limit on outside diameter }\left(m_{4}(x)\right)=\frac{x_{1}+x_{2}}{1.5}-1 \leq 0
$$

where $0.05 \leq x_{1} \leq 0.25,0.25 \leq x_{2} \leq 1.30$ and $2.00 \leq x_{3} \leq 15.0$.

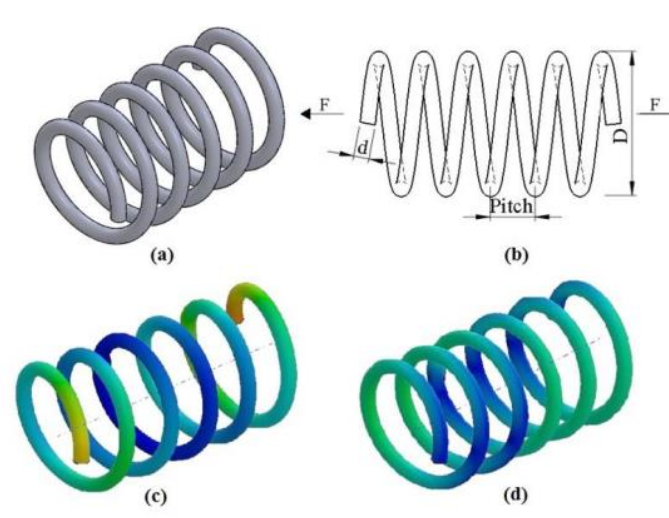

Figure 6. a) 3D view of the spring b) $2 \mathrm{D}$ view of the spring c) displacement heat map d) stress heat map

There are three design variables: wire diameter $d\left(x_{1}\right)$, mean coil diameter $D\left(x_{2}\right)$ and the number of active coils $N\left(x_{3}\right)$. Table 12 compares the best optimal solution obtained using HSSASCA algorithm with those reported in the literature. It can be easily seen that the minimum weight value $(0.12533670077042)$ obtained by the proposed method is better than those of the others.

Table 12. Best solutions of the tension/compression spring design by different algorithms

\begin{tabular}{ccccc}
\hline Algorithm & $x_{1}$ & $x_{2}$ & $x_{3}$ & $f(x)$ \\
\hline IHS [49] & 0.05115438 & 0.34987116 & 12.0764321 & 0.0126706 \\
ABC [38] & 0.051749 & 0.358179 & 11.203763 & 0.012665 \\
MFO [8] & 0.051994457 & 0.36410932 & 10.868421862 & 0.0126669 \\
GWO [13] & 0.05169 & 0.356737 & 11.28885 & 0.012666 \\
AFA [50] & 0.0516674837 & 0.3561976945 & 11.3195613646 & 0.0126653049 \\
BA [51] & 0.05169 & 0.35673 & 11.2885 & 0.01267 \\
LSA-SM [43] & 0.05170453 & 0.3570899 & 11.26718 & 0.01266524 \\
HSSASCA & $\mathbf{0 . 0 5 1 5 9 1}$ & $\mathbf{0 . 3 5 6 9 4 5 8}$ & $\mathbf{1 1 . 1 9 2 5 3}$ & $\mathbf{0 . 1 2 5 3 3 6 7 0 0 7 7 0 4 2}$ \\
\hline
\end{tabular}




\subsection{Cantilever Beam Design}

This Cantilever beam problem [26] has been solved in this section. The main objective is to find the best and possible minimum weight of this function. The section 4, presents all parameter settings on which a newly approach code has been run for searching the completive or best solution of this function. Figure 7, represents a schematic view of this function. The mathematical explanation of this function has been presented as following.

$$
\begin{aligned}
& \text { Minimize: } f(x)=0.0624\left(x_{1}+x_{2}+x_{3}+x_{4}+x_{5}\right) \\
& \text { Subject to: } g(x)=\frac{61}{x_{1}^{3}}+\frac{37}{x_{2}^{3}}+\frac{19}{x_{3}^{3}}+\frac{7}{x_{4}^{3}}+\frac{1}{x_{5}^{3}}-1 \leq 0
\end{aligned}
$$

where $0.01 \leq x_{j} \leq 100 ; j=1,2, \ldots, 5$.

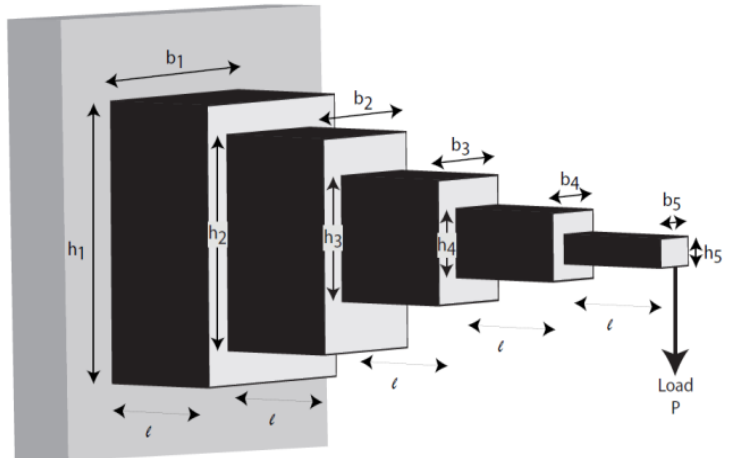

Figure 7. The cantilever beam design problem

$$
\begin{gathered}
b_{i} \sim \text { width } \\
h_{i} \sim \text { height } \\
p \sim \text { load }
\end{gathered}
$$

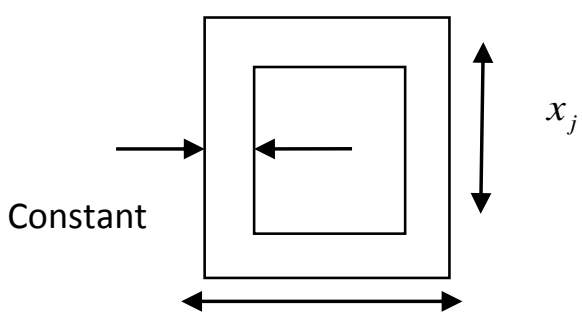

For the purpose of comparison, we use the results of the recent comparative algorithms 1.e. Method of moving asymptotes (MMA) [20], cuckoo search (CS) [20], generalized convex approximation -I (GCA-I) [10], generalized convex approximation-II (GCA-II) [10], symbiotic organisms search (SOS) [9], Moth Flame Optimizer (MFO) [33] and lightning search algorithm simplex method (LSA-SM) [26].Hence, after assessment of the results can be easily concluded that the HSSASCA algorithm provides in comparison to others the minimum value of weight of the Cantilever Beam Design problem. The minimum weight value of HSSASCA algorithm achieves the overall best design of 1.338896 (See Table 13).

Table 13. Best solutions of the Cantilever Beam Design by different algorithms

\begin{tabular}{ccccccc}
\hline Algorithm & I & II & III & IV & V & $\begin{array}{c}\text { Minimum } \\
\text { Weight Value }\end{array}$ \\
\hline & $x_{1}$ & $x_{2}$ & $x_{3}$ & $x_{4}$ & $x_{5}$ & \\
MMA & 6.0100 & 5.3000 & 4.4900 & 3.4900 & 2.1500 & 1.3400 \\
CS & 6.0089 & 5.3049 & 4.5023 & 3.5077 & 2.1504 & 1.33999 \\
GCA-I & 6.0100 & 5.3000 & 4.4900 & 3.4900 & 2.1500 & 1.3400 \\
GCA-II & 6.0100 & 5.3000 & 4.4900 & 3.4900 & 2.1500 & 1.3400 \\
SOS & 6.01878 & 5.30344 & 4.49587 & 3.49896 & 2.15564 & 1.33996 \\
MFO & 5.98487177 & 5.316726924 & 4.49733258 & 3.51361646 & 2.16162029 & 1.33998808 \\
LSA-SM & 6.021636 & 5.310859 & 4.490882 & 3.497403 & 2.152906 & 1.339958 \\
HSSASCA & $\mathbf{6 . 0 1 2 5 3 4}$ & $\mathbf{5 . 3 0 1 4 5 2}$ & $\mathbf{4 . 4 9 1 5 4 6}$ & $\mathbf{3 . 4 9 6 5 8 2}$ & $\mathbf{2 . 1 5 4 5 2 6}$ & $\mathbf{1 . 3 3 8 8 9 6}$ \\
\hline
\end{tabular}




\section{CONCLUSION}

In this paper, we developed a new hybrid algorithm that integrates salp swarm (SSA) and sine cosine algorithms (SCA) for enhancing exploitation of the standard algorithms. The performance of the hybrid algorithm has been assessed and compared against seven feature selection approaches including SSA, PSO, MFO, SCA, DA, MVO, ALO, MGWO, DCSGWO, FWAGWO and HAGWO. Different criteria have been reported namely the minimum and maximum objective function value, standard deviation, best score, average, self and total time. On the basis of convergence performance of the proposed algorithm, we can conclude that the new hybrid approach is highly capable for maintaining balance amid exploitation and exploration. At the end, the proposed algorithm has been applied to solve three engineering design problems in reality namely three-bar truss, tension/compression spring and cantilever beam design problems. The experimental numerical and statistical results/or solutions reveal that the proposed hybrid method is better to other competitors in terms of convergence speed, quality of solutions and can serve as an efficient and capable computer aided tool for real life tasks with complex search area.

Future studies will investigate a new method to accelerate the speed of HSSASCA as well as apply it for solving other constrained nonlinear optimization functions [62-75].

\section{ACKNOWLEDGEMENT}

The authors are very grateful to the referees for their valuable suggestions, which helped to improve the quality of the paper significantly.

\section{REFERENCES}

[1]. Abido MA. Optimal power flow using tabu search algorithm. Electric Power Compon Syst. 2002;30:469-83.

[2]. Abtahi AR, Bijari A. A novel hybrid meta-heuristic technique applied to the well-known benchmark optimization problems. Journal of Industrial Engineering International. 2017:13(1):93-105.

[3]. Akay B, Karaboga D. Artificial bee colony algorithm for large-scale problems and engineering design optimization. Journal of Intelligent Manufacturing. 2012:23(4):1001-1014.

[4]. Bakirtzis AG, Biskas P, Zoumas CE, Petridis V. Optimal power flow by enhanced genetic algorithm. Power Syst, IEEE Trans.2002;17(2): 229-236.

[5]. Barraza J, Rodriguez L, Castillo O, Melin P, Valdez F. A New Hybridization Approach between the Fireworks Algorithm and Grey Wolf Optimizer Algorithm. Journal of Optimization. 2018: Article id: 6495362: 1-18.

[6]. Baykasoğlu A, Ozsoydan FB. Adaptive firefly algorithm with chaos for mechanical design optimization problems. Applied Soft Computing. 2015:1(36):152-164.

[7]. Ben-Tal A, El haoui, L, Nemirovski, A. Robust Optimization. Princeton Series in Applied Mathematics. Princeton University Press. 2009:9-16.

[8]. Bouchekara HREH. Optimal power flow using black-hole-based optimization approach. Appl. Soft Comput. 2014;24: 879-888.

[9]. Cheng MY, Prayogo D. Symbiotic organisms search: a new meta-heuristic optimization algorithm. Computers \& Structures. 2014:139: 98-112.

[10]. Chickermane H, Gea HC. Structural optimization using a new local approximation method. International Journal for Numerical Methods in Engineering. 1996:39(5):829-846.

[11]. Chowdhury BH. Towards the concept of integrated security: optimal dispatch under static and dynamic security constraints. Electric Power Syst, Research.1992; 25:213-225.

[12]. Chung TS and Li YZ. A hybrid GA approaches for OPF with consideration of FACTS devices. IEEE Power Engineering Review. 2001: 47-50.

[13]. Daryani N, Hagh MT, Teimourzadeh S. Adaptive group search optimization algorithm for multi-objective optimal power flow problem. Appl. Soft Comput.2016;38:1012-1024.

[14]. Derrac J, García S, Molina D, Herrera F. A practical tutorial on the use of nonparametric statistical tests as a methodology for comparing evolutionary and swarm intelligence algorithms. Swarm and Evolutionary Computation. 2011:1(1):3-18.

[15]. Duman S, Güvenç U, Sönmez Y, Yörükeren N. Optimal power flow using gravitational search 
algorithm. Energy Convers, Manag. 2012;59:86-95.

[16]. Faris H, Mafarja MM, Heidari AA, Aljarah I, Ala'M AZ, Mirjalili S, Fujita H. An Efficient Binary Salp Swarm Algorithm with Crossover Scheme for Feature Selection Problems. Knowledge-Based Systems.2018.

[17]. Fouad A. A Hybrid Grey Wolf Optimizer and genetic algorithm for minimizing potential energy function. Memetic Computing. 2017:9(9):1-13.

[18]. Gandomi AH, Yang XS, Alavi AH, Talatahari H. Bat algorithm for constrained optimization tasks. Neural Computing and Applications. 2013:22(6):1239-1255.

[19]. Gandomi AH, Yang XS, Alavi AH. Cuckoo search algorithm: a metaheuristic approach to solve structural optimization problems. Engineering with Computers. 2013:29(1):17-35.

[20]. Gandomi AH, Yang XS, Alavi AH. Cuckoo search algorithm: a metaheuristic approach to solve structural optimization problems. Engineering with Computers. 2013:29(1):17-35.

[21]. Hsun LR, Ren TS, Tone CY. Tseng Wan-Tsun. Optimal power flow by a fuzzy based hybrid particle swarm optimization approach. Electr Power Syst Res 2011;81(7):1466-74.

[22]. Kalaiselvi K, Kumar V, Chandrasekar K. Enhanced Genetic Algorithm for Optimal Electric Power Flow using TCSC and TCPS. Proc. World. 2010.(II)

[23]. Kennedy J, Eberhart RC. Particle Swarm Optimization. In: Proceedings of IEEE International Conference on Neural Networks,.1995:1942-1948.

[24]. Liu H, Cai Z, Wang Y. Hybridizing particle swarm optimization with differential evolution for constrained numerical and engineering optimization. Applied Soft Computing, 2010:10(2): 629-640.

[25]. Liu H, Hua G, Yin H, Xu Y. An Intelligent Grey Wolf Optimizer Algorithm for Distributed Compressed Sensing. Computational Intelligence and Neuroscience. 2018: Article id: 1723191: $1-10$.

[26]. Lu Y, Zhou Y, Wu X. A Hybrid Lightning Search Algorithm-Simplex Method for Global Optimization. Discrete Dynamics in Nature and Society. 2017: 2017(2017):id: 8342694:1-23.

[27]. Mahdavi M, Fesanghary M, Damangir E. An improved harmony search algorithm for solving optimization problems. Applied Mathematics and Computation. 2007:188(2):1567-1579.

[28]. Mirjalili S, Gandomi AH, Mirjalili SZ, Saremi S, Faris H, Mirjalili SM. Salp swarm algorithm: a bio-inspired optimizer for engineering design problems. Advances in Engineering Software. 2017:114:163-191.

[29]. Mirjalili S, Mirjalili SM, Hatamlou A. Multi-Verse Optimizer: a nature-inspired algorithm for global optimization. Neural Computing and Applications.2016; 2:495-513.

[30]. Mirjalili S, Mirjalili SM, Lewis A. Grey Wolf Optimization. Advance in Engineering Software. 2014;69:46-61.

[31]. Mirjalili S. Dragonfly algorithm: a new meta-heuristic optimization technique for solving single-objective, discrete, and multi-objective problems. Neural Computing and Applications. 2016;4:1053-1073.

[32]. Mirjalili S. Grasshopper Optimization Algorithm: Theory and application. Advances in Engineering Software. 2016;105:30-47.

[33]. Mirjalili S. Moth-flame optimization algorithm: A novel nature-inspired heuristic paradigm. Knowlede-Based System, Elsevier. 2015;89:228-249.

[34]. Mirjalili S. SCA: A Sine Cosine Algorithm for solving optimization problems. KnowledeBased System, Elsevier. 2016;96:120-133.

[35]. Mirjalili S. The Whale Optimization Algorithm. Advances in Engineering Software. 2016;9:5167.

[36]. Mirjalili, S. The Ant Lion Optimizer. Advances in Engineering Software. Elsevier. 2015; 83:8098.

[37]. Mukherjee A, Mukherjee V. Solution of optimal power flow using chaotic krill herd algorithm. Chaos. Solutions \& Fractals. 2015;78:10-21.

[38]. Pandiri, V., \& Singh, A. A swarm intelligence approach for the colored traveling salesman problem. Applied Intelligence. 2018: 1-17. DOI: 10.1007/s10489-018-1216-0.

[39]. Rao MR, Babu NVN. Optimal Power Flow Using Cuckoo Optimization Algorithm. Ijareeie.2013:4213-4218.

[40]. Ray T, Liew KM. Society and civilization: an optimization algorithm based on the simulation of social behavior. IEEE Transactions on Evolutionary Computation. 2003:7(4):386-396.

[41]. Sadollah A, Bahreininejad A, Eskandar H, Hamdi M. Mine blast algorithm: a new population based algorithm for solving constrained engineering optimization problems. Applied Soft 
Computing.2013:13(5): 2592-2612.

[42]. Sarbazfard S, Jafarian A. A Hybrid Algorithm based on Firefly Algorithm and Differential Evolution for Global Optimization. International Journal of Advanced Computer Science and Applications. 2016:7(6):95-106.

[43]. Sayed GI, Khoriba G, Haggag MH. A novel chaotic salp swarm algorithm for global optimization and feature selection. Applied Intelligence. 2018:6:1-20.

[44]. Sayed, G. I., Khoriba, G., \& Haggag, M. H. A novel chaotic salp swarm algorithm for global optimization and feature selection. Applied Intelligence. 2018: 1-20. DOI: 10.1007/s10489-0181158-6.

[45]. Simon D. Biogeography-based optimization. IEEE Transaction on Evolutionary Computation. 2008;12(6):702-713.

[46]. Singh N, Hachimi H. A New Hybrid Whale Optimizer Algorithm with Mean Strategy of Grey Wolf Optimizer for Global Optimization. Mathematical and Computational Applications.2018:23(14):1-32.

[47]. Singh N, Singh S, Singh SB. A New Hybrid MGBPSO-GSA Variant for Improving Function Optimization Solution in Search Space. Evolutionary Bioinformatics. 2017:13:1-13.

[48]. Singh N, Singh S, Singh SB. Half Mean Particle Swarm Optimization Algorithm. International Journal of Scientific \& Engineering Research.2012:3(8):1-9.

[49]. Singh N, Singh SB. A Modified Mean Grey Wolf Optimization Approach for Benchmark and Biomedical Problems. Evolutionary Bioinformatics.2017:13:1-28.

[50]. Singh N, Singh SB. Hybrid Algorithm of Particle Swarm Optimization and Grey Wolf Optimizer for Improving Convergence Performance. Journal of Applied Mathematics.2017:ID 2030489:1-15.

[51]. Singh N, Singh SB. Personal Best Position Particle Swarm Optimization. Journal of Applied Computer Science \& Mathematics. 2012:12(6):69-76.

[52]. Singh N, Singh, SB. One Half Global Best Position Particle Swarm Optimization Algorithm. International Journal of Scientific \& Engineering Research. 2011:2(8):1-10.

[53]. Singh N. A Modified Variant of Grey Wolf Optimizer. International Journal of Science \& Technology, Scientia Iranica. 2018. In press:

http://scientiairanica.sharif.edu/?_action=article\&keywords=A+Modified+Variant+of+Grey+W olf+Optimizer

[54]. Sinsupan N, Leeton U, Kulworawanichpong T. Application of Harmony Search to Optimal Power Flow Problems 2010:219-222.

[55]. Soares J, Sousa T. Vale ZA, Morais H, Faria P. Ant colony search algorithm for the optimal power flow problem. IEEE Power Energy Soc, Gen, Meet. 2011: 1-8.

[56]. Tawhid MA, Savsani V. Multi-objective sine-cosine algorithm (MO-SCA) for multi-objective engineering design problems. Neural Computing and Applications. 2017:1-15.

[57]. Wolpert DH, Macready WG. No Free Lunch Theorems for Optimization. IEEE Transactions on Evolutionary Computation. 1997:1(1):67-82.

[58]. Yang, Y., Yang, B., \&Niu, M. Adaptive infinite impulse response system identification using opposition based hybrid coral reefs optimization algorithm. Applied Intelligence. 2017: 1-18. DOI: 10.1007/s10489-017-1034-9.

[59]. Yuan X, Dai X, Zhao J, He Q. On a novel multi-swarm fruit fly optimization algorithm and its application. Applied Mathematics and Computation. 2014:233(3):260-271.

[60]. Zhang M, Luo W, Wang X. Differential evolution with dynamic stochastic selection for constrained optimization. Information Sciences.2008:178(15):3043-3074.

[61]. Zhao, X., Hwang, J. N., Fang, Z., \& Wang, G. Gradient-based adaptive particle swarm optimizer with improved extremal optimization. Applied Intelligence. 2018: 1-14. DOI: 10.1007/s10489-018-1228-9.

[62]. Amal, L., Son, LH, Chabchoub, H. SGA: spatial GIS-based genetic algorithm for route optimization of municipal solid waste collection. Environmental Science and Pollution Research. 2018: 1-14. DOI: 10.1007/s11356-018-2826-0.

[63]. Son, LH, Fujita, H. (2018). Neural-Fuzzy with Representative Sets for Prediction of Student Performance. Applied Intelligence. 2018: 1-8.

[64]. Le, T., Le Son, H., Vo, M. T., Lee, M. Y., \& Baik, S. W. A Cluster-Based Boosting Algorithm for Bankruptcy Prediction in a Highly Imbalanced Dataset. Symmetry (20738994), 2018: 10(7).

[65]. Son, LH, Chiclana, F., Kumar, R., Mittal, M., Khari, M., Chatterjee, J. M., \& Baik, S. W. ARM-AMO: An efficient association rule mining algorithm based on animal migration 
optimization. Knowledge-Based Systems, 154. 2018: 68-80.

[66]. Ngan, R. T., Son, LH, Cuong, B. C., \& Ali, M. H-max distance measure of intuitionistic fuzzy sets in decision making. Applied Soft Computing, 69. 2018: 393-425.

[67]. Hemanth, D. J., Anitha, J., Son, LH. Brain signal based human emotion analysis by circular back propagation and Deep Kohonen Neural Networks. Computers \& Electrical Engineering, 68. 2018: 170-180.

[68]. Pham, B. T., Son, LH, Hoang, T. A., Nguyen, D. M., \& Bui, D. T. Prediction of shear strength of soft soil using machine learning methods. Catena, 166. 2018: 181-191.

[69]. Louati, A., Son, LH \& Chabchoub, H. Smart routing for municipal solid waste collection: a heuristic approach. Journal of Ambient Intelligence and Humanized Computing. 2018: 1-20. DOI: 10.1007/s12652-018-0778-3.

[70]. Singh, K., Singh, K., Son, LH \& Aziz, A. Congestion control in wireless sensor networks by hybrid multi-objective optimization algorithm. Computer Networks, 138. 2018: 90-107.

[71]. Giap, C. N., Son, L. H., \& Chiclana, F. Dynamic structural neural network. Journal of Intelligent \& Fuzzy Systems, 34. 2018: 2479 - 2490.

[72]. Ali, M., Son, LH, Thanh, N. D., \& Van Minh, N. (2017). A neutrosophic recommender system for medical diagnosis based on algebraic neutrosophic measures. Applied Soft Computing. DOI: $10.1016 /$ j.asoc.2017.10.012

[73]. Chuan, P. M., Son, LH, Ali, M., Khang, T. D., \& Dey, N. Link prediction in co-authorship networks based on hybrid content similarity metric. Applied Intelligence, 48(8). 2018: 24702486.

[74]. Hemanth, D. J., Anitha, J., Popescu, D. E., \& Son, L. H. A modified genetic algorithm for performance improvement of transform based image steganography systems. Journal of Intelligent \& Fuzzy Systems, 35(1). 2018: 197-209.

[75]. Ali, M., Son, LH, Khan, M., \& Tung, N. T. Segmentation of dental X-ray images in medical imaging using neutrosophic orthogonal matrices. Expert Systems with Applications, 91. 2018: 434-441.

[76]. Singh, N. and Singh, S.B. A novel hybrid GWO-SCA approach for optimization problem. Engineering Science and Technology, an International Journal, 20.2017:1586-1601.

[77]. Farnad, B. and Jafarian, A. Anew nature-inspired hybrid algorithm with a penalty method to solve constrained problem. International Journal of Computational Methods,15(08).2018.

[78]. Awais, M., Javaid, N., Mateen, A., Khan, N., Mohiuddin, A., Rehman and M.H.A. In the proceeding of $32^{\text {nd }}$ International Conference on Advanced Information Networking and Applications, IEEE, 2018:882-891.

[79]. Marzie, A., Haddad, O.B. and Chu, X. Flower Pollination Algorithm (FPA). In Advanced Optimization by Nature-Inspired Algorithms, Springer, 2018:59-67.

[80]. Abdel-Basset, M., Gunasekaran, M., El-Shahat, D., Mirjalili, S. A hybrid whale optimization algorithm based on local search strategy for the permutation flow shop scheduling problem. Future Generation Computer Systems, 85.2018:129-145.

[81]. Zamli, K.Z., Din, F., S.Ahmed, B. and Bures, M. A hybrid Q-learning sine-cosine-based strategy for addressing the combinatorial test suite minimization problem. PLoS ONE, 13(5).2018.

[82]. Vidal, T., Crainic, T.G., Gendreau, M., Prins, C. A hybrid genetic algorithm with adaptive diversity management for a large class of vehicle routing problems with time- window. Computers \& Operation Research, Elsevier, 40(1).2013:475-489.

[83]. Zheng, Y.J. Water wave optimization: A new nature-inspired metaheuristic. Computers \& Operation Research, Elsevier, 55(1).2015: 1-11.

[84]. Yang, X.S. Nature-Inspired Optimization Algorithms. Book, Elsevier Science Publishers B. V. Amsterdam, The Netherlands, The Netherlands. 2014. https://dl.acm.org/citation.cfm?id $=2655295$.

[85]. Hu, C., Xia, Y. and Zhang, J. Adaptive Operator Quantum-Behaved Pigeon-Inspired Optimization Algorithm with Application to UAV Path Planning. Algorithms, MDPI. 12(1). 2018:1-16.

[86]. Talbi, E.G. A taxonomy of hybrid metaheuristics. Journal of Heuristics, 8(5).2002:541-564. 


\section{Appendix:}

Table A. Uni-modal functions

\begin{tabular}{lccc}
\hline Function & Dim & Range & $f_{\min }$ \\
\hline$F_{1}(x)=\sum_{i=1}^{n} x_{i}^{2}$ & 30 & {$[-100,100]$} & 0 \\
$F_{2}(x)=\sum_{i=1}^{n}\left|x_{i}\right|+\prod_{i=1}^{n}\left|x_{i}\right|$ & 30 & {$[-10,10]$} & 0 \\
$F_{3}(x)=\sum_{i=1}^{n}\left(\sum_{j-1}^{i} x_{j}\right)^{2}$ & 30 & {$[-100,100]$} & 0 \\
$F_{4}(x)=\max _{i}\left\{\left|x_{i}\right|, 1 \leq i \leq n\right\}$ & 30 & {$[-100,100]$} & 0 \\
$F_{5}(x)=\sum_{i=1}^{n-1}\left[100\left(x_{i+1}-x_{i}^{2}\right)^{2}+\left(x_{i}-1\right)^{2}\right]$ & 30 & {$[-30,30]$} & 0 \\
$F_{6}(x)=\sum_{i=1}^{n}\left(\left[x_{i}+0.5\right]\right)^{2}$ & 30 & {$[-100,100]$} & 0 \\
$F_{7}(x)=\sum_{i=1}^{n} i x_{i}^{4}+\operatorname{rand}[0,1)$ & 30 & {$[-1.28,1.28]$} & 0
\end{tabular}

Table B. Multi-modal functions

\begin{tabular}{lccc}
\hline Function & Dim & Range & $f_{\min }$ \\
\hline$F_{8}(x)=\sum_{i=1}^{n}-x_{i} \sin \left(\sqrt{\left|x_{i}\right|}\right)$ & 30 & {$[-500,500]$} & $\begin{array}{c}-418.9829 \\
\times 5\end{array}$ \\
$F_{9}(x)=\sum_{i=1}^{n}\left[x_{i}^{2}-10 \cos \left(2 \pi x_{i}\right)+10\right]$ & 30 & {$[-5.12,5.12]$} & 0 \\
$F_{10}(x)=-20 \exp \left(-0.2 \sqrt{\frac{1}{n} \sum_{i=1}^{n} x_{i}^{2}}\right)$ & 30 & {$[-32,32]$} & 0 \\
$-\exp \left(\frac{1}{n} \sum_{i=1}^{n} \cos \left(2 \pi x_{i}\right)\right)+20+e$ & & & \\
$F_{11}(x)=\frac{1}{4000} \sum_{i=1}^{n} x_{i}^{2}-\prod_{i=1}^{n} \cos \left(\frac{x_{i}}{\sqrt{i}}\right)+1$ & 30 & {$[-600,600]$} & 0
\end{tabular}




$$
\begin{aligned}
& F_{12}(x)=\frac{\pi}{n}\left\{10 \sin \left(\pi y_{i}\right)+\sum_{i=1}^{n-1}\left(y_{i}-1\right)^{2}\left[1+10 \sin ^{2}\left(30 y_{i+1}\right)+\left(\left[y_{n-1} 5_{0}\right)\right]\right\}\right] \quad 0 \\
& +\sum_{i=1}^{n} u\left(x_{i}, 10,100,4\right) \\
& y_{i}=1+\frac{x_{i}+1}{4} \\
& u\left(x_{i}, a, k, m\right)=\left\{\begin{array}{cc}
k\left(x_{i}-a\right)^{m} & x_{i}>a \\
0 & -a<x_{i}<a \\
k\left(-x_{i}-a\right)^{m} & x_{i}<-a
\end{array}\right. \\
& F_{13}(x)=0.1\left\{\sin ^{2}\left(3 \pi x_{i}\right)+\sum_{i=1}^{n}\left(x_{i}-1\right)^{2}\left[1+\sin ^{2}\left(3 \pi x_{i}+3 \phi\right]+\left(x_{n}-11\right) 5\left[5150 i i^{2}\left(2 \pi x_{n}\right)\right]\right\}\right. \\
& +\sum_{i=1}^{n} u\left(x_{i}, 5,100,4\right)
\end{aligned}
$$

Table C. Fixed-dimension multi-modal benchmark functions

$$
\begin{aligned}
& \begin{array}{llll}
\hline \text { Function } & \text { Dim } & \text { Range } & f_{\min } \\
F_{14}(x)=\left(\frac{1}{500}+\sum_{j=1}^{25} \frac{1}{j+\sum_{i=1}^{2}\left(x_{i}-a_{i j}\right)^{6}}\right)^{-1} & 2 & {[-65,65]} & 1
\end{array} \\
& F_{15}(x)=\sum_{i=1}^{11}\left[a_{i}-\frac{x_{1}\left(b_{i}^{2}+b_{i} x_{2}\right)}{b_{i}^{2}+b_{i} x_{i}+x_{4}}\right]^{2} \quad 4 \quad[-5,5] \quad 0.00030 \\
& F_{16}(x)=4 x_{1}^{2}-2.1 x_{1}^{4}+\frac{1}{3} x_{1}^{6} \quad 2 \quad[-5,5] \quad-1.0316 \\
& +x_{1} x_{2}-4 x_{2}^{2}+4 x_{2}^{4} \\
& F_{17}(x)=\left[1+\left(x_{1}+x_{2}+1\right)^{2}\left(\begin{array}{l}
19-14 x_{1}+3 x_{1}^{2} \\
-14 x_{2}+6 x_{1} x_{2}+3 x_{2}^{2}
\end{array}\right)\right] \quad 2 \quad[-2,2] \\
& \left.\times\left[\begin{array}{l}
30+\left(2 x_{1}-3 x_{2}\right)^{2} \\
\times\left(18-32 x_{1}+12 x_{1}^{2}\right. \\
+48 x_{2}-36 x_{1} x_{2}+27 x_{2}^{2}
\end{array}\right)\right] \\
& F_{18}(x)=-\sum_{i=1}^{4} c_{i} \exp \left(-\sum_{j=1}^{3} a_{i j}\left(x_{j}-p_{i j}\right)^{2}\right) \quad 3 \quad[1,3] \quad-3.86 \\
& F_{19}(x)=-\sum_{i=1}^{4} c_{i} \exp \left(-\sum_{j=1}^{6} a_{i j}\left(x_{j}-p_{i j}\right)^{2}\right) \quad 6 \quad[0,1] \quad-3.32
\end{aligned}
$$




$$
\begin{array}{llll}
F_{20}(x)=-\sum_{i=1}^{5}\left[\left(X-a_{i}\right)\left(X-a_{i}\right)^{T}+c_{i}\right]^{-1} & 4 & {[0,10]} & -10.1532 \\
F_{21}(x)=-\sum_{i=1}^{7}\left[\left(X-a_{i}\right)\left(X-a_{i}\right)^{T}+c_{i}\right]^{-1} & 4 & {[0,10]} & -10.4028 \\
F_{22}(x)=-\sum_{i=1}^{10}\left[\left(X-a_{i}\right)\left(X-a_{i}\right)^{T}+c_{i}\right]^{-1} & 4 & {[0,10]} & -10.5363
\end{array}
$$

